\title{
Contriving a chimeric polyvalent vaccine to prevent infections caused by Herpes Simplex Virus (Type-1 and Type-2): an exploratory immunoinformatic approach
}

\author{
Athours' name: \\ Mahmudul Hasan ${ }^{1,2}$, Md Shiful Islam ${ }^{3}$, Sourav Chakraborty ${ }^{4}$, Abu Hasnat Mustafa ${ }^{4}$, Kazi \\ Faizul Azim ${ }^{1,5}$, Ziaul Faruque Joy,6, Md Nazmul Hossain ${ }^{1,5}$, Shakhawat Hossain Foysal ${ }^{4}$, Md \\ Nazmul Hasan ${ }^{4}$
}

\section{Affiliation:}

${ }^{1}$ Faculty of Biotechnology and Genetic Engineering, Sylhet Agricultural University, Sylhet3100, Bangladesh

${ }^{2}$ Department of Pharmaceuticals and Industrial Biotechnology, Sylhet Agricultural University, Sylhet-3100, Bangladesh

${ }^{3}$ Department of Biochemistry and Molecular Biology, Shahjalal University of Science and Technology, Sylhet-3114, Bangladesh

${ }^{4}$ Department of Genetic Engineering and Biotechnology, Shahjalal University of Science and Technology, Sylhet-3114, Bangladesh

${ }^{5}$ Department of Microbial Biotechnology, Sylhet Agricultural University, Sylhet-3100, Bangladesh

${ }^{6}$ Department of Biomedical Science, University of Sheffield, United Kingdom

\section{Corresponding author:}

Mahmudul Hasan

Assistant Professor

Department of Pharmaceuticals and Industrial Biotechnology

Faculty of Biotechnology and Genetic Engineering

Sylhet Agricultural University, Sylhet-3100

E-mail: mhasan.pib@sau.ac.bd, hasan_sust@yahoo.com

Telephone: 008801723698461

ORCID ID: https://orcid.org/0000-0003-4761-2111 


\begin{abstract}
Herpes simplex virus type 1 (HSV-1) and 2 (HSV-2) cause a variety of infections including oral-facial infections, genital herpes, herpes keratitis, cutaneous infection and so on. To date, FDA-approved licensed HSV vaccine is not available yet. Hence, the study was conducted to identify and characterize an effective epitope based polyvalent vaccine against both types of Herpes Simplex Virus through targeting six viral proteins. The selected proteins were retrieved from viralzone and assessed to design highly antigenic epitopes by binding analyses of the peptides with MHC class-I and class-II molecules, antigenicity screening, transmembrane topology screening, allergenicity and toxicity assessment, population coverage analysis and molecular docking approach. The final vaccine was constructed by the combination of top CTL, HTL and BCL epitopes from each protein along with suitable adjuvant and linkers. Physicochemical and secondary structure analysis, disulfide engineering, molecular dynamic simulation and codon adaptation were further employed to develop a unique multi-epitope peptide vaccine. Docking analysis of the refined vaccine structure with different MHC molecules and human immune TLR-2 receptor demonstrated higher interaction. Complexed structure of the modeled vaccine and TLR-2 showed minimal deformability at molecular level. Moreover, translational potency and microbial expression of the modeled vaccine was analyzed with $\mathrm{pET} 28 \mathrm{a}(+)$ vector for $E$. coli strain strain K12. The study enabled design of a novel chimeric polyvalent vaccine to confer broad range immunity against both HSV serotypes. However, further wet lab based research using model animals are highly recommended to experimentally validate our findings.
\end{abstract}

Keywords: herpes simplex virus; genital herpes; polyvalent vaccine; immunoinformatics; disulfide engineering; TLR-2 


\section{Introduction}

Herpes simplex virus 1 (HSV-1) and herpes simplex virus2 (HSV-2) are the two members of the Herpesviridae family. Oro-labial infection, mostly caused by HSV-1 is found in children while HSV-2 has been associated with genital disorders (Nahmias et al., 1990; Lafferty et al., 1987). Symptomatic HSV-1 infections are usually manifested as recurrent oro-labial and facial lesions. On the other hand, HSV-2 infections are usually symptomatic and are typically characterized by recurrent, painful vesicular and ulcerative lesions in the genital and anal areas (Corey \& Wald, 1999; Stanberry et al., 1997; Kimberlin \& Rouse, 2004). In addition, genital herpes may lead substantial psychological morbidity (Patel et al., 2001). Moreover, HSV-2 infection has received renewed attention in recent years as the epidemiological synergy between HSV-2 and HIV has been revealed. It has been claimed that HSV-2 infection increases the risk of HIV acquisition by approximately three-fold (Freeman et al., 2006; Brown et al., 2007; Reynolds et al., 2003). Some serious diseases such as blindness, encephalitis and neonatal infections are also being reported for both HSV-1 and HSV-2 infections (Stanberry et al., 1997).

Both of HSV-1 and HSV-2 are ubiquitous and contagious in nature (Ryan \& Ray, 2004). Recent data have claimed that HSV-1 is involved in substantial proportion of genital herpes infections, particularly in Europe (Lowhagen et al., 2002; Lafferty et al., 2017; Strutt et al., 2003; Scoular et al., 2002; Christie et al., 1997). In the United States, HSV-1 infections have been found surprisingly in college-students and other selected populations (Lafferty et al., 2000; Ribes et al., 2001; Roberts et al., 2003; Langenberg et al., 1999). Besides, 50\% of the adults were seropositive for HSV-1 and about $15 \%$ of those who were sexually active were infected by HSV-2 (McQuillan et al., 2018; Xu et al., 2018; Roberts et al., 2003; Looker et al., 2017). Literature review suggests that 536 million people exhibited existing (prevalent) and 23.6 million people had new (incident) HSV-2 infection all over the world (Looker et al., 2012) where more women (267 million) than men (150 million) had prevalent infection. Greater biological susceptibility to HSV-2 by women may be attributed to the most likely reason for this [Holmes et al., 2008; Corey et al., 2004; Kaushic et al., 2011; Glynn et al., 2001). The global burden of HSV infection is huge, exposing more than 400 million people at increased risk of genital ulcer disease, transmission of HSV-2 to partners or neonates and HIV acquisition. These estimates highlight the critical need for development of vaccines and other new prevention strategies to combat HSV associated infections (Looker et al., 2012). 
Despite the deliberate research for more than 60 years, development of an effective HSV vaccine has remained elusive and challenging. To date, FDA-approved licensed HSV vaccine is not available yet (Whitley \& Baines, 2018). Vaccine development is still complicated owing to some unique characteristics of herpes viruses which include complexity of the virus replication cycle (i.e., primary, latent and recurrent phases of infection), sophisticated immune evasion strategies of the virus, a high number of protein candidates by the large and complex herpes genome (Dasgupta et al., 2009). Development of vaccines often requires prior understanding of the immunological insights during the natural course of an infection. So far, researcher are trying to test efficacy of four types of experimental vaccines against HSV (Raghuwanshi et al., 2018) which are classical formalin-inactivated crude or partially purified infected cell extract, semi-purified or highly purified infected cell extract showing low concentration of non-viral proteins and a minimum of residual vDNA, recombinant virus glycoproteins along with nonstructural polypeptides prepared as fusion proteins and live attenuated HSV1 or HSV2 virus vaccine. Though many attempts have been taken, neither a therapeutic nor preventive vaccine exists for HSV-1 or HSV-2 (Whitley \& Baines, 2018). Many vaccines were investigated which ultimately yielded disappointing results in human trials (Whitley \& Baines, 2018). The development of several promising HSV vaccines has been terminated recently due to modest or controversial therapeutic effects in humans (Whitley and Baines, 2018). A vaccine trial named VICal was terminated in June 2018 as the magnitude of the effect in the test population was unsatisfactory (Whitley \& Baines, 2018; Veselenak et al., 2012). Genocea, a company in USA has confirmed not to develop its GEN003 vaccine anymore after results from a partially conducted phase III trial revealed its limited clinical efficacy (Whitley \& Baines, 2018; Skoberne et al., 2013). A prophylactic vaccine also failed to prevent HSV-2 infection and diseases in clinical trials (Belshe et al., 2012) where the study population was representative of the general population of HSV-1 and HSV-2 seronegative women (Veselenak et al., 2012). The vaccine was effective in preventing HSV-1 genital disease but not in preventing HSV-2 infection. Overall, the vaccine was not efficacious (20\%) (Veselenak et al., 2012). If a vaccine were found to give type-common protection against both HSV-1 and HSV-2, early childhood vaccination would have been optimal (Koelle et al., 2003).

However, Conventional vaccines development by either attenuated or inactivated whole pathogen witnessed a number of limitations (Rappuoli, 2000; Purcell et al., 2007). First, 
genetic variations of pathogens around the globemay results in reduced efficiency of these vaccines in distinctive parts of the world. Second, enormous vaccine trials failed to reach in phase III (Sabchareon et al., 2012; Gray et al., 2011; Tameris et al., 2013). Third, experimental assay based identification of conserved regions that maintain their structure and function of glycoprotein is a tedious process (Rappuoli, 2000). Such shorts of limitation apparently indicates the better understanding of host pathogen interaction, focusing prior insilico study before lab based preparation of vaccines (Mora et al., 2003; Rappuoli et al., 2016). Immunoinformatics, an emerging field of the present era addressed the complex biological shortcomings of decrypting the immune response for vaccine designing and development (Nielsen et al., 2007). For completely eradicating the chance of re-infection, an ideal vaccine has to initiate humoral or cell mediated immunity. The Cytotoxic $\mathrm{T}$ lymphocytes (CTL) and Helper T lymphocytes (HTL) recognize the foreign antigen that are presented by Major Histocompatibility Complex (MHC) and expressed on the surface of all nucleated cells. T-cell epitope prediction tools help to identify allele specific peptides. Hence, it reduces the number of potential peptides to be considered as vaccine candidates. In silico epitope predictions tools have already proved advantages in determining the potential candidates reducing the number of validation experiments and time (Korber et al., 2006; Nielsen et al., 2007). In recent times, enormous computational tools are available for predicting peptides ( $\mathrm{T}$ and $\mathrm{B}$ cell) with necessary properties for vaccine design (Yang \& Yu 2009). On top of that, several works were done by the researcher working on in silico vaccine design of several deadly and worrisome viruses including Nipah (Saha et al., 2017), Ebola (Dash et al., 2017), HIV (Saxena et al., 2013; Yang et al., 2015) etc. But still now, no attempt has been taken for determining in silico vaccine target against both types of HSV. Therefore, the present research will be a promising study for the computer aided design of epitope based vaccine target against Type-1 and Type-2 HSV in together. Meanwhile, the study could be useful for laboratory based development of effective multiepitope polyvalent vaccine as well as further development of existing experimental subunit vaccines of HSV.

\section{Materials and methods}

In the present study, an immunoinformatic approach was adopted for predicting vaccine candidates against Type-1 and Type-2 Herpes Simplex Virus (HSV). The flow chart summarizing the protocol over in silico vaccinomics strategy for designing a unique multiepitope subunit vaccine has been illustrated in figure 1 . 


\section{Selection of Viral strain and retrieval of protein sequences}

The National Center for Biotechnology Information (NCBI) provides access to biomedical and genomic information over many organisms. The server was used for the selection of Type-1 Herpes Simplex Virus (HSV) (https://www.ncbi.nlm.nih.gov/genome/). Study of other associated information including the genus, family, host, transmission, disease, genome and proteome analysis were performed by using ViralZone, a web-resource of Swiss Institute of Bioinformatics (https://viralzone.expasy.org/). A total 6 glycoproteins were considered as vaccine targets for in silico analysis and vaccine development against HSV.

\section{Retrieval of homologous protein sets and multiple sequence alignment}

Homologous sequences of the selected glycoproteins were retrieved from the NCBI database by using BLASTp tool. All 6 glycoproteins were used as query and the searches were restricted to Type-1 HSV (Taxid: 10298) and Type-2 HSV (Taxid: 10310). Multiple sequence alignment (MSA) was further performed to find out the common regions for both sets of proteins using using MEGA 5.05 software package (http://www.megasoftware.net). The CLUSTALW algorithm along with 1000 bootstrap value and other default parameters were used to fabricate the alignment. The sequences were investigated in order to recognize the immunologically pertinent regions that were achieved by predicting epitopic peptides.

\section{Prediction of antigenicity and transmembrane properties of the conserved sequences}

Antigenicity refers to the capacity of antigens to be recognized by the by the antibodies or immune system. The conserved amino acid sequences from each of the 6 proteins were screened for predicting their antigenicity using an online antigen prediction server, VaxiJen v2.0 (Doytchinova \& Flower, 2007). Each selected conserved fragments were subjected to transmembrane topology prophecy using TMHMM v0.2 server (Krogh et al., 2001) with a view to discriminate intracellular and surface proteins with high degree of accuracy. 


\section{Prediction of T Cell Epitopes from the Conserved Regions}

Both MHC-I restricted CD8+ cytotoxic T lymphocytes (CTLs) and MHC-II restricted CD4+ cytotoxic $\mathrm{T}$ lymphocytes play a pivotal role in controlling viral infections. Hence, identification of $\mathrm{T}$ cell epitopes is crucial for understanding the mechanism of $\mathrm{T}$ cell activation and epitope driven vaccine design. The IEDB offers easy searching of experimental data characterizing antibody and $\mathrm{T}$ cell epitopes studied in human and other non-human primates. From this Immune Epitope Database, MHC-I prediction tool (http://tools.iedb.org/mhci/) and MHC-II prediction tool (http://tools.iedb.org/mhcii/) were used to predict the MHC-I binding and MHC-II binding respectively (Vita et al., 2014).

\section{Transmembrane topology prediction and antigenicity analysis of epitopes}

The TMHMM server (http://www.cbs.dtu.dk/services/TMHMM/) predicted the transmembrane helices in proteins. The topology was determined according to the position of the transmembrane helices separated by ' $\mathrm{i}$ ' if the loop is on the inside or ' $\mathrm{o}$ ' if it is on the outside (Krogh et al., 2001). Again, VaxiJen v2.0 server (http://www.ddgpharmfac.net/vaxijen/) was used to determine the epitope antigenicity (Doytchinova and Flower, 2007). The most potent antigenic epitopes were selected for further investigation.

\section{Population coverage analysis}

HLA distribution varies among different ethnic groups and geographic regions around the world. In this study, population coverage for each individual epitope was analyzed by the IEDB population coverage calculation tool analysis resource (http://tools.iedb.org/population/).

\section{Allergenicity assessment and toxicity analysis of T-Cell epitopes}

The prediction of allergens has been explored widely using bioinformatics, with many tools being developed in the last decade. Four different tools, i.e.AllerTOP (http://www.ddgpharmfac.net/AllerTop/) (Dimitrov et al., 2013), AllergenFP (http://www.ddgpharmfac.net/AllergenFP/) (Dimitrov et al., 2014), PA3P (http://www.Ipa.saogabriel.unipampa.edu.br:8080/pa3p/) (Chrysostomou \& Seker, 2014) and Allermatch (http:// www.allermatch.org/allermatch.py/form) (Fiers et al., 2004) were used to 
predict the allergenicity of our proposed epitopes for vaccine development. Only the nonallergenic epitopes were allowed to demonstrate the toxicity level by ToxinPred server (http://crdd.osdd.net/raghava/toxinpred/).

\section{Conservancy analysis}

Epitope conservancy is a vital step in the immunoinformatic approach as it determines the extent of desired epitope distributions in the homologous protein set. IEDB's epitope conservancy analysis tool (http://tools.iedb.org/conservancy/) was selected for the analysis of conservancy level by concentrating on the identities of the selected proteins.

\section{Designing three-dimensional (3D) epitope structure}

The top ranked epitopes were subjected for the docking study after analyzing through different bioinformatics tools. PEP-FOLD is a de novo approach aimed at predicting peptide structures from amino acid sequences (Maupetit et al., 2010). By Folding peptides on a user specified patch of a protein, it comes with the possibility to generate candidate conformations of peptide-protein complexes (Kaur et al., 2007). The server was used to design and retrieve the $3 \mathrm{D}$ structure of most potent selected epitopes for further analysis.

\section{Molecular docking analysis}

MGLTools is a software developed for the visualization and analysis of molecular structures (Sanner, 1999). It includes AutoDock, an automated docking software designed to predict the interactions between small molecules (i.e. substrates or drug candidates) and receptor of known 3D structure (Morris et al., 2009). All the operations were performed at $1.00^{\circ} \mathrm{A}$ space keeping the exhaustiveness parameter at 8.00. The numbers of outputs were set at 10 . The docking was conducted using AutoDOCKVina program based on the above-mentioned parameters. OpenBabel (version 2.3.1) was used to convert the output PDBQT files in PDB format. The best output was selected on the basis of higher binding energy. The docking interaction was visualized with the PyMOL molecular graphics system, version 1.5.0.4 (https://www.pymol.org/). 


\section{B-Cell epitope identification}

B cell epitope prediction tools from IEDB were used to identify the B cell antigenicity based on six different algorithms which include Emini surface accessibility prediction (Emini et al., 1985), Karplus and Schulz flexibility prediction (Karplus \& Schulz, 1985), Bepipred linear epitope prediction analysis (Jespersen et al., 2017), Chou and Fasman beta turn prediction (Chou \& Fasman, 1978), Kolaskar \& Tongaonkar antigenicity scale (Kolaskar \& Tongaonkar, 1990) and Parker hydrophilicity prediction (Parker et al., 1986).

\section{Vaccine construction}

Subunit vaccines consist of antigenic parts of a pathogen to stimulate an immunogenic reaction in the host. The predicted T-cell and B-cell epitopes were conjugated in a sequential manner to design the final vaccine construct. All three vaccine proteins started with an adjuvant followed by the top CTL epitopes for both capsid protein VP1 and protein VP2, then by top HTL epitopes and BCL epitopes respectively, in the similar fashion. Three vaccine sequence were constructed named V1, V2 and V3, each associated with different adjuvants including beta defensin (a 45 mer peptide), L7/L12 ribosomal protein and HABA protein ( $M$. tuberculosis, accession number: AGV15514.1). Interactions of adjuvants with toll like receptors (TLRs) polarize CTL responses and induce robust immunoreactions (Rana and Akhter, 2016). Beta defensin adjuvant can act as an agonist to TLR1, TLR2 and TLR4 receptor. On the contrary, L7/L12 ribosomal protein and HBHA protein are agonists to TLR4 only. To overcome the problems caused by highly polymorphic HLA alleles, PADRE sequence was also incorporated along with the adjuvant peptides. EAAAK linkers were used to join the adjuvant and CTL epitopes. Similarly, GGGS, GPGPG and KK linkers were used to conjugate the CTL, HTL and BCL epitopes respectively. Utilized linkers ensured the effective separation of individual epitopes in vivo (Hajighahramani et al., 2017; Pandey et al., 2016).

\section{Allergenicity and antigenicity prediction of different vaccine constructs}

AlgPred v.2.0 (Saha and Raghava, 2000) sever was used to predict the non-allergic nature of the constructed vaccines. The server developed an algorithm by considering the auto cross covariance transformation of proteins into uniform vectors of similar length. The accuracy of 
results ranges from $70 \%$ to $89 \%$ depending on species. We further used VaxiJen v2.0 server (Doytchinova and Flower, 2007) to evaluate the probable antigenicity of the vaccine constructs in order to suggest the superior vaccine candidate. The server analyzed the immunogenic potential of the given proteins through an alignment-independent algorithm.

\section{Physicochemical characterization and secondary structure analysis of vaccine protein}

ProtParam, a tool provided by Expasy server (Gasteiger et al., 2003; Hasan et al., 2015a; Das et al., 2016) was used to functionally characterize the vaccine constructs according to molecular weight, aliphatic index, isoelectric $\mathrm{pH}$, hydropathicity, instability index, GRAVY values, estimated half-life and various physicochemical properties. By comparing the $\mathrm{pK}$ values of different amino acids, the server computes these parameters of a given protein sequence. Aliphatic index is the volume occupied by the aliphatic side chains of protein. Grand average of hydropathicity was computed by summing the hydropathicity of all amino acid residues present in the protein sequenceand then by dividing it by total number of amino acid residues. The PSIPRED v3.3 (Kosciolek \& Jones, 2014) and NetTurnP 1.0 program (Petersen et al., 2010; Thaysen-Andersen \& Packer, 2012) was used to predict the alpha helix, beta sheet and coil structure of the vaccine constructs.

\section{Vaccine tertiary structure prediction, refinement and validation}

The RaptorX server performed 3D modeling of the designed vaccines depending on the degree of similarity between target protein and available template structure from PDB (Kallberg et al., 2014; Peng and Xu, 2011). Refinement was conducted using ModRefiner (Xu and Zhang, 2011) followed by FG-MD refinement server (Zhang et al., 2011) to improve the accuracy of the predicted 3D modeled structure. ModRefiner drew the initial model closer to its native state based on hydrogen bonds, side-chain positioning and backbone topology, thus resulting in significant improvement in the physical quality of the local structure. FGMD is another molecular dynamics based algorithm for structure refinement at atomic level. The refined protein structure was further validated by Ramachandran plot assessment at RAMPAGE (Lovell et al., 2002; Hasan et al., 2015b). 


\section{Vaccine protein disulfide engineering}

Disulfide bonds enhance the geometric conformation of proteins and provide significant stability. DbD2, an online tool was used to design such bonds for the constructed vaccine protein (Craig \& Dombkowski, 2013). The server detects and provides a list of residue pairs with proper geometry which have the capacity to form disulfide bond when individual amino acids are mutated to cysteine.

\section{Protein-protein docking}

Molecular docking aims to determine the binding affinity between a receptor molecule and ligand (Solanki \& Tiwari, 2018). An approach for protein-protein docking was employed to determine the binding affinity of designed subunit vaccines with different HLA alleles and TLR-2 immune receptor by using ClusPro 2.0 (Comeau et al., 2004), hdoc (Macalino et al., 2018; Kangueane \& Nilofer, 2018) and PatchDock server (Schneidman-Duhovny et al., 2005). During HSV infection, viral glycoproteins on the envelope serve as PAMPs for TLR2 and act as a ligand (Leoni et al., 2012; Sato et al., 2006). The 3D structure of different MHC molecules and human TLR-2 receptor was retrieved from RCSB protein data bank. The above mentioned servers were used to obtain the desirable complexes in terms of better electrostatic interaction and free binding energy. PatchDock generated a number of solutions which were again subjected to the FireDock server to refine the complexes.

\section{Molecular dynamics simulation}

Molecular dynamics study is important to strengthen any in silico prediction and demonstrate the stability of protein-protein complex. Stability can be determined by comparing the essential dynamics of proteins to their normal modes (Aalten et al., 1997; Wuthrich et al., 1980). This powerful tool is an alternative to the costly atomistic simulation (Tama \& Brooks, 2006; Cui \& Bahar, 2007). iMODS server explains the collective motion of proteins by analyzing the normal modes (NMA) in internal coordinates (Lopez-Blanco et al., 2017). The structural dynamics of protein complex was investigated by using this server due to its much faster and effective assessments than other molecular dynamics (MD) simulations tools (Awan et al., 2017; Prabhakar et al., 2016). It predicted the direction and extent of the immanent motions of the complex in terms of deformability, eigenvalues, B-factors and 
covariance. The deformability of the main chain depends on the ability to deform at each of its residues for a given molecule. The eigenvalue related to each normal mode describes the motion stiffness. This value is directly linked to the energy required to deform the structure. Deformation is much easier if the eigenvalue is low and vice versa (Lopez-Blanco et al., 2011).

\section{Codon adaptation and in silico cloning}

Codon adaptation tools are used for adapting the codon usage to the well characterized prokaryotic organisms to accelerate the expression rate in them. E. coli strain K12 was selected as host for cloning purpose of the designed vaccine construct. Due to the lack of similarities between the codon usage of human and E. coli, the approach was adopted to achieve higher expression of vaccine protein V1 in the selected host. Rho independent transcription termination, prokaryote ribosome-binding site and cleavage sites of several restriction enzymes (i.e. XhoI and EcoRI) were avoided during the operation performed by JCAT server (Grote et al., 2005). The optimized sequence of vaccine protein V1 was reversed and then conjugated with XhoI and EcoRI restriction site at the N-terminal and C-terminal sites respectively. SnapGene (Solanki \& Tiwari, 2018) restriction cloning module was used to insert the adapted sequence between XhoI (158) and EcoRI (192) of pET28a(+) vector.

\section{Results}

\section{Retrieval of Protein Sequences}

The sequences of 6 glycoproteins i.e. GP B39, GP C, GP D, GP E, GP G and envelope protein UL45 of Type-1 Herpes Simplex virus were retrieved from NCBI protein database(http://www.ncbi.nlm.nih.gov/protein) in FASTA format. Again, 6 sets of homologous proteins for each glycoproteins were generated after BLASTp search using NCBI BLAST tools (Supplementary file 1-6). Each set comprisedprotein sequences belonging to different isolates of Type-1 and Type-2 HSV. 


\section{Identification and Selection of Conserved Sequences}

A total of 27, 17, 14, 21, 15 and 7 conserved sequences were found inGP B39, GP C, GP D, GP E, GP G and envelope protein UL45, respectively. Conserved sequences generated in this method have been presented in supplementary file 7-12.

\section{Antigenicity and Transmembrane Properties of the Conserved Sequences}

Results showed that 20,10, 9, 10, 11 and 2conserved sequencesfrom GP B39, GP C, GP D, GP E, GP G and GP UL45 respectively met the criteria of default threshold level in VaxiJen (Table 1). Moreover, transmembrane topology screening revealed, among the immunogenic conserved sequences8, 2, 5, 3, 8 and 2 sequences from the corresponding proteins fulfilled the criteria of exomembrane characteristics (Table 1).

\section{T-Cell epitope prediction}

Numerous immunogenic epitopes from the selected proteins were identified to be potent $\mathrm{T}$ cell epitopes using both MHC-I and MHC- II binding predictions of IEDB. Epitopes that bind to the maximum number of HLA cells with high binding affinity were selected (Table 2 and Table 3).

\section{Transmembrane topology prediction and antigenicity analysis}

Top epitopes from both proteins were selected as putative $\mathrm{T}$ cell epitope candidates based on their transmembrane topology screening and antigenic scoring (Table 2 and Table 3). Epitopes with a positive score of immunogenicity exhibited potential to elicit effective T-cell response.

\section{Allergenicity assessment and toxicity analysis of T-Cell epitopes}

Based on the allergenicity assessment by four servers (i.e. AllerTOP, AllergenFP, $\mathrm{PA}^{3} \mathrm{P}$, Allermatch), epitopes that were found to be non-allergen for human were identified (Table 2 and Table 3). Epitopes those were indicated as allergen for human and classified as toxic or undefined were removed from the predicted list of epitopes. 


\section{Population coverage analysis}

All indicated alleles in supplementary data were identified as optimum binders with the predicted epitopes and were used to determine the population coverage. Population coverage results for six glucoproteins are shown in figure 2.

\section{Conservancy analysis}

Putative epitopes generated from 6 glycoproteins were found to be highly conserved with conservancy level ranging from $90 \%$ to $100 \%$. The top epitopes showing conservancy at a superior level were allowed for further docking study and used to construct the final vaccine candidates to ensure a broad spectrum vaccine efficacy.

\section{Molecular docking analysis and HLA allele interaction}

11 T-cell epitopes were subjected to PEP-FOLD3 web-based server for 3D structure conversion in order to analyze their interactions with HLA molecules. On the basis of available Protein Data Bank (PDB) structures deposited in the database, HLA-A*11:01, HLA-A*02:06 and HLA-DRB1*01:01was selected for docking analysis and the binding energies were analyzed (Table 4). Results showed that all the predicted epitopes bound in the groove of MHCmolecules with a negative bindingenergy which were biologically significantly (Table 4, Figure 3 and Figure 4).

\section{B-Cell epitope identification}

B cell epitopes were predicted according to the analysis via four different algorithms from IEDB. Top BCL epitopes for selected six glycoproteins were further screened based on their antigenicity scoring and allergenicity pattern.The top BCL epitope for each protein was used to design the final vaccine construct (Table 5).

\section{Vaccine construction}

Each of the constructs consisted of a protein adjuvant followed by PADRE peptide sequence, while the rest was occupied by the T-cell and B-cell epitopes and their respective linkers. PADRE sequence was incorporated to maximize the efficacy and potency of the peptide 
vaccine. All three designed vaccines comprised 6 CTL epitopes, 6 HTL epitopes and 8 BCL epitopes combined together in a sequential manner. A total 3 vaccines of 403 (V1), 488 (V2) and 517 (V3) amino acid long were constructed (Table 6) and further analyzed to investigate their immunogenic potential.

\section{Allergenicity and antigenicity prediction of different vaccine constructs}

Results showed that all three constructs (V1, V2 and V3) were non-allergic in behavior. However, V1 was best in terms of safety and found superior as potential vaccine candidate with better antigenicity (0.772) and ability to stimulate preferred immune response (Table 6).

\section{Physicochemical characterization of vaccine protein}

The final vaccine construct was characterized on the basis of physical and chemical properties. The molecular weight of the vaccine construct V1 was $33.83 \mathrm{kDa}$ which ensured its good antigenic potential. The theoretical pI 10.33 indicated that the protein will have net negative charge above the $\mathrm{pI}$ and vice versa. The extinction coefficient was 40450, assuming all cysteine residues are reduced at $0.1 \%$ absorption. The estimated half-life of the constructed vaccine was expected to be $1 \mathrm{~h}$ in mammalian reticulocytes in vitro while more than $10 \mathrm{~h}$ in $E$. coli in vivo. Thermostability and hydrophilic nature of the vaccine protein was represented by aliphatic index and GRAVY value which were 91.55 and 0.229 respectively. The computed instability index of the protein was 34.91 which classified it as a stable one.

\section{Secondary and tertiary structure prediction}

Secondary structure of the construct V1 confirmed to have $30.44 \%$ alpha helix, $21.79 \%$ sheet and $47.77 \%$ coil structure (Fig. 6). RaptorX generated the tertiary structure of the designed construct V1 consisting single domain (Figure 5). Homologymodeling was performed by detecting and using 1vh4A from protein data bank (PDB) as best suited template for Vaccine V1. All 335 amino acid residues (100\%) were modeled with only $15 \%$ residues in the disordered region. The quality of the $3 \mathrm{D}$ model was defined by $\mathrm{P}$ value which was $2.12 \mathrm{e}^{-03}$ for the predicted vaccine protein. The low $\mathrm{P}$ value ensured better model quality of the predicted vaccine. 


\section{Tertiary structure refinement and validation}

Refinement was performed to improve the quality of predicted 3D modeled structure beyond the accuracy. Before refinement Ramachandran plot analysis revealed that $92.2 \%$ residues were in the favored, $6.3 \%$ residues in the allowed and $1.5 \%$ residues in the outlier region. However, after refinement $95.5 \%$ and $4.2 \%$ residues were in the favored and allowed region respectively, while only $0.3 \%$ residues were found in the outlier region (Figure 6). Modeled tertiary structure of vaccine construct V2 and V3 have been shown in figure 7.

\section{Vaccine protein disulfide engineering}

Residues in the highly mobile region of the protein sequence were mutated with cysteine to perform Disulfide engineering. A total 54 pairs of amino acid residue were identified having the capability to form disulfide bond by $\mathrm{DbD} 2$ server. After evaluation of the residue pairs in terms of energy, chi3 and B-factor parameter, only 2 pair satisfied the disulfide bond formation. Those residue pairs were GLY 82-GLY 121 and ALA 105-GLY 136 and LYS 284ARG287 (Figure 8). All these 4 residues were replaced with cysteine residue. The value of chi3 considered for the residue screening was between -87 to +97 while the energy value was less than 2.5 .

\section{Protein-protein docking}

Docking analysis was performed between vaccine construct and different HLA alleles (Table 7). Construct V1 showed biologically significant results in terms of free binding energy. Besides, docking was also conducted to evaluate the binding affinity of designed vaccine with human TLR2 receptor using ClusPro, hdoc and PatchDock web servers (Figure 9). The ClusPro server generated 30 protein-ligand complexes as output along with respective free binding energy. The lowest energy of -1200.2 was obtained for the complex named cluster 1 . The hdoc server predicted the binding energy for the protein-protein complex was -293.17 , while FireDock output refinement of Patch Dock server showed the lowest global energy of 28.07 for solution 7. The lowest binding energy of the complexes indicates the highest binding affinity between TLR-8 and vaccine construct. 


\section{Molecular dynamics simulation}

Normal mode analysis (NMA) was performed throughiMODS server by considering the internal coordinates of the docked complex. The deformabilty of the complex depends on the individual distortion of each residues, represented by hinges in the chain (Figure 10:B). The eigenvalue found for the complex was 1.051e-05 (Figure 10:D). There was an inverse relationship between eigenvalue and the variance associated to each normal mode (Figure 10:C). The B-factor values inferred via NMA, was equivalent to RMS (Figure 10:A). Coupling between pairs of residues was indicated by the covariance matrix where different pairs showed correlated, uncorrelated or anti-correlated motions, represented by red, white and blue colors respectively (Figure 10:E). An elastic network model was also generated (Figure 10:F) according to the level of stiffness between the pairs of atoms connected via springs (the darker the grays, the stiffer the springs).

\section{Codon adaptation and in silico cloning}

Due to dissimilarity in the regulatory systems of human and E. coli, codon adaptation was performed considering the expression system of the host. Construct V1 was reversetranscribed where in the adapted codons, codon adaptation index (CAI) was 0.968 ensuring the higher proportion of most abundant codons. The GC content of the optimized codons (53.081\%) was significant as well. The construct did not contain restriction sites for XhoI and EcoRI and thus indicating its safety for cloning purpose. Finally, the optimized codons were inserted into pET28a(+) vector along with XhoI and EcoRI restriction sites. A clone of 6346 base pair was produced comprising 1011bp desired sequence (shown in red color in between the sequence of $\mathrm{pET} 28 \mathrm{a}(+)$ vector and the rest belonging to the vector only (Figure 11).

\section{Discussion}

Although studies regarding HSV have been performed extensively over the last six decades, development of an effective vaccine has remained still challenging (Whitley \& Baines, 2018). No FDA verified effective vaccine has been reported that can prevent the spread or acquisition of either HSV serotype (Whitley \& Baines, 2018; Boukhvalova et al., 2005). Hence, the present study aids in the path of broad spectrum vaccine development against 
HSV. The conventional approaches for vaccine development may take decades to experimentally validate and commercialize a product in the drug market (Babu et al., 2014; Hasan et al., 2019a). These include live or attenuated vaccines which require in vitro culture and antigen expression. Moreover most of the techniques used so far to purge antigens resulted in undesirable consequences (Rappuoli, 2000) or adverse reactions (Purcell et al., 2007; Wong et al., 2014). In this study we focused on a different strategy by taking the advantages of genome and proteome database through adopting reverse vaccinology approach (Azim et al., 2019; Hasan et al., 2015b).

The major glycoproteins (six) of Herpes Simplex Virus was retrieved in FASTA format and investigated through BLASTp analysis to find the homologous protein sets (>90\% identity) for each glycoprotein. The retrieved protein sequences belong to different strains of Type-1 and Type-2 Herpes Simplex Virus isolated from different geographic regions. Multiple sequence alignment (MSA) allowed identification of the conserved regions among these proteins. This step was followed by the prediction of potential B-cell and T-cell epitopes for each glycoproteins separately. Cytotoxic CD8+T lymphocytes (CTL) control the spread of infectious agents by recognizing and killing infected cells or secreting specific antiviral cytokines (Garcia et al., 1999). Thus, T cell epitope-based vaccination is a unique process to stimulate strong defensive response against infectious pathogen (Shrestha, 2004). However, most vaccines trigger both $\mathrm{T}$ cell and $\mathrm{B}$ cell response. Vaccine induces production of antibodies that are synthesized by B cells and mediates effector functions by interacting specifically to a pathogen or toxin (Cooper \& Nemerow, 1984). Here, the most immunogenic epitopes for HTL, CTL and BCL receptors were screened through analyzing antigenicity, allergenicity, toxicity, conservancy and other physiochemical properties using a number of bioinfomatics tools. The top and finalized epitopes used to design the final vaccine constructs were validated through molecular docking approach with corresponding HLA alleles (Table 4). Predicted CTL, HTL and BCL epitopes from each protein were combined together using suitable linkers and adjuvant to develop a novel multiepitope polyvalent vaccine against Herpes Simplex Virus. It has been reported that PADRE sequence reduces the polymorphism of HLA molecules in the population (Ghaffari-Nazari et al., 2015). Therefore it was also incorporated to construct the final vaccines in this study. The selected adjuvants and linkers were used to enhance the immunogenicity and effective separation of epitopes within host (Yang et al., 2015). 
Moreover, the designed vaccines were characterized based on allergenicity, antigenicity, physiochemical properties, three dimensional structure, di-sulfide engineering and stability. Construct V1 was superior and found best considering each parameter discussed above. Finally, the molecular docking and dynamics study was performed to investigate the binding affinity and complex stability of the vaccine with different HLA molecules (i.e. DRB $1 * 0101$, DRB3*0202, DRB5*0101, DRB3*0101, DRB1*0401, and DRB1*0301) and human TLR-2 receptor. The vaccine-TLR2 complex showed minimum deformability at molecular level which further strengthened our prediction. In-silico cloning was conducted to ensure the stability and effective expression of designed vaccine construct.

\section{Conclusion}

In-silico studies can guide experimental works with higher probabilities of finding the appropriate solutions through fewer trials and error repeats thus saving time and costs for the researchers. In this study, we developed a unique chimeric vaccine with the potential to confer immunity against both type (Type-1 and Type-2) of Herpes Simplex Virus and the expression system was also analyzed. Our predicted results were based on diligent analysis of sequence and various immune databases. However, further in vivo trials using model organisms are highly recommended to validate our findings.

\section{Acknowledgments}

Authors like to acknowledge the authority of the Bioinformatics Laboratory of Sylhet Agricultural University for the technical support of the project.

\section{Funding}

This research did not receive any specific grant from funding agencies in the public, commercial, or not-for-profit sectors.

\section{Conflict of interest}

Authors declare no conflict of interests. 


\section{Author contributions}

Mahmudul Hasan: Conceptualization, Supervision, Project Administration and Reviewing; Shiful Islam: Experiment Design, Data Handling, T-Cell Epitope Prediction and Docking Study

Sourav Chakraborty: Experiment Design, Data Handling and B-Cell Epitope Prediction Abu Hasnat Mustafa: Data Handling, Conservancy Analysis and Docking Study Kazi Faizul Azim: Data Handling, Data Analysis, Vaccine Modeling, Manuscript writing Ziaul Faruque Joy: Simulation Study and Expression Analysis

Md Nazmul Hossain: Data Organization, Manuscript writing

Shakhawat Hossain Foysal: Data Organization, Disulfide Engineering and Homology modeling

Md Nazmul Hasan: Population Coverage Study and Manuscript Reviewing

\section{References}

Aalten DMF, Groot BL, Findlay JBC, Berendsen HJC, Amadei A. A Comparison of Techniques for Calculating Protein Essential Dynamics. Journal of Computational Chemistry. 1997;18(2):169 -181.

Awan FM, Obaid A, Ikram A, Janjua HA. Mutation-structure function relationship based integrated strategy reveals the potential impact of deleterious missense mutations in autophagy related proteins on hepatocellular carcinoma (HCC): a comprehensive informatics approach. Int J Mol Sci. 2017;18(1):139.

Azim KF, Hasan M, Hossain MN, Somana SR, Hoque SF, et al. Immunoinformatics approaches for designing a novel multiepitope peptide vaccine against human norovirus (Norwalk virus). Vaccine. 2019.

Babu TM, Levine M, Fitzgerald T, Luke C, Sangster MY, Jin H, et al. Live attenuated H7N7 influenza vaccine primes for a vigorous antibody response to inactivated H7N7 influenza vaccine. Vaccine. 2014;32:6798-804. 
Belshe RB, Leone PA, Bernstein DI, Wald A, Levin MJ, et al. Efficacy results of a trial of a herpes simplex vaccine. N Engl J Med. 2012;366:34-43.

Boukhvalova M, McKay J, Mbaye A, Sanford-Crane H, Blancho JCG, et al. Efficacy of the Herpes Simplex Vaccine 2 (HSV-2) Glycoprotein D/AS04 Vaccine against Genital HSV-2 and HSV-1 Infection and Disease in the Cotton rat Sigmodon hispidus Model. J Virol. 2015;89(19):9825-9840.

Brown JM, Wald A, Hubbard A, Rungruengthanakit K, Chipato T, et al. Incident and prevalent herpes simplex virus type 2 infection increases risk of HIV acquisition among women in Uganda and Zimbabwe. AIDS. 2007;21:1515-1523.

Chou P, Fasman G. Prediction of the secondary structure of proteins from their amino acid sequence. Adv Enzymol. 1978;47:45-148.

Christie SN, McCaughey C, McBride M, et al. Herpes simplex type 1 and genital herpes in Northern Ireland. Int J STD AIDS. 1997;8:68-9.

Chrysostomou C, Seker H. Prediction of protein allergenicity based on signal-processing bioinformatics approach. $36^{\text {th }}$ annual international conference of the IEEE engineering in medicine and biology society. 2014:808-811.

Comeau SR, Gatchell DW, Vajda S, Camacho CJ. ClusPro: a fully automated algorithm for protein-protein docking. Nucl Acids Res. 2004;32:W96-9.

Cooper NR, Nemerow GR. The role of antibody and complement in the control of viral infections. J Invest Dermatol 1984;83:121-7.

Corey L, Wald A, Patel R, Sacks SL, Tyring SK, et al. Once-daily valacyclovir to reduce the riskof transmission of genital herpes. N Engl J Med. 2004;350:11-20.

Corey L, Wald A. Genital herpes. In: Holmes KK, Sparling FP, Mardh PA, et al, editors. Sexually Transmitted Diseases. 3rd ed. New York, NY: McGraw-Hill;1999:285-312.

Craig DB, Dombkowski AA. Disulfide by Design 2.0: a web-based tool for disulfide engineering in proteins. BMC Bioinformatics. 2013;14:346.

Cui Q, Bahar I. normal mode analysis theoretical and applications to biological and chemical systems. Briefing in Bioinformatics. 2007;8(5):378-379. 
Das K, Chakraborty S, Hasan M, Shovo AM. In silico analysis to elect superior bacterial alkaline protease for detergent and leather industries. 2016;5:685-698.

Dasgupta G, Chentoufi AA, Nesburn AB, Wechsler SL, BenMohamed L. New concepts in herpes simplex virus vaccine development: notes from the battlefield. Expert Rev Vaccines. 2009;8(8):1023-1035.

Dash R, Das R, Junaid M, Akash MF, Islam A, Hosen SZ. In silico-based vaccine design against Ebola virus glycoprotein. Adv Appl Bioinform Chem. 2017;10:11-28.

Dimitrov I, Bangov I, Flower DR, Doytchinova1 I. AllerTOP v.2- a server for in silico prediction of allergens. J. of Molecular Modeling. 2013;20:2278.

Dimitrov I, Naneva L, Doytchinova1 I and Bangov I. AllergenFP: allergenicity prediction by descriptor fingerprints. Bioinformatics. 2014;30:846-851.

Doytchinova IA, Flower DR. Identifying candidate subunit vaccines using an alignmentindependent method based on principal amino acid properties. Vaccine. 2007 25:856-866.

Doytchinova IA, Flower DR. VaxiJen: a server for prediction of protective antigens, tumour antigens and subunit vaccines. BMC Bioinformatics. 2007;8:4.

Emini EA, Hughes JV, Perlow D, Boger J. Induction of hepatitis A virus-neutralizing antibody by a virus-specific synthetic peptide. Journal of virology. 1985;55:836-9.

Fiers M WEJ, Kleter GA, Nijland H, Peijnenburg A, Nap JP and Ham R. Allermatch ${ }^{\mathrm{TM}}$, a webtool for the prediction of potential allergenicity according to current FAO/WHO Codex alimentarius guidelines BMC Bioinformatics. 2004;5:133.

Freeman EE, Weiss HA, Glynn JR, Cross PL, Whitworth JA, et al. Herpes simplex virus 2 infection increases HIV acquisition in men and women: systematic review and meta-analysis of longitudinal studies. AIDS. 2006;20:73-83.

Garcia KC, Teyton L, Wilson IA. Structural basis of T cell recognition. Annual Review of Immunology 1999;17:369-97.

Gasteiger E, Hoogland C, GattikerA, Duvaud S, Wilkins MR, Appel RD, Bairoch A. Protein Identification and Analysis Tools on the ExPASy Server. Nucleic Acids Res. 2003;31:37843788. 
Ghaffari-Nazari H, Tavakkol-Afshari J, Jaafari MR, Tahaghoghi-Hajghorbani S, Masoumi E, Jalali SA. Improving Multi-Epitope Long Peptide Vaccine Potency by Using a Strategy that Enhances CD4+T Help in BALB/c Mice. PloS one. 2015;10:e0142563.

Glynn JR, Carael M, Auvert B, Kahindo M, Chege J, et al. Why do young women have a muchhigher prevalence of HIV than young men? A study in Kisumu, Kenya and Ndola, Zambia. AIDS. 2001;15 Suppl 4:S51-60.

Gray GE, Allen M, Moodie Z, Churchyard G, Bekker LG, et al. Safety and efficacy of the HVTN 503/Phambili study of a clade-B-based HIV-1 vaccine in South Africa: a double-blind, randomised, placebo-controlled test-of-concept phase $2 b$ study. Lancet Infect Dis. 2011;11:507-515.

Grote A, Hiller K, Scheer M, Münch R, Nortemann B, Hempel DC,et al. JCat: a novel tool to adapt codon usage of a target gene to its potential expression host. Nucleic acids research. 2005;33:W526-531.

Hajighahramani N, Nezafat N, Eslami M, Negahdaripour M, Rahmatabadi SS, Ghasemi Y. Immunoinformatics analysis and in silico designing of a novel multi-epitope peptide vaccine against Staphylococcus aureus. Infect Genet Evol. 2017;48:83-94.

Hasan M, Azim KF, Begum A, Khan NA, Shammi TS, Imran AS, Chowdhury IM, Urme SR. Vaccinomics strategy for developing a unique multi-epitope monovalent vaccine against Marburg marburgvirus. Infection, Genetics and Evolution. 2019a;70:140-157.

Hasan M, Ghosh P, Azim K, Mukta S, Abir RA, Nahar J, Khan MM. Reverse vaccinology approach to design a novel multi-epitope subunit vaccine against avian influenza A (H7N9) virus. Microbial pathogenesis. 2019b;130:19-37

Hasan M, Hakim A, Iqbal A, Bhuiyan FR, Begum MK, Sharmin S and Abir RA. Computational study and homology modeling of phenol hydroxylase: key enzyme for phenol degradation. Int J Comput Bioinfo In Silico Model. 2015b;4(4):691-698.

Hasan M, Joy ZF, Bhuiyan EH, Islam MS. In Silico Characterization and Motif Election of Neurotoxins from Snake Venom. American Journal of Biochemistry \& Biotechnology. 2015a;11(2):84. 
Holmes KK, Sparling PF, Stamm WE, Piot P, Wasserheit J, et al. Sexually TransmittedDiseases; Chapter 24: Genital Herpes: McGraw-Hill Medical. 2008.

Jespersen MC, Peters B, Nielsen M, Marcatili P. BepiPred-2.0: improving sequence-based Bcell epitope prediction using conformational epitopes. Nucleic acids research. 2017;45:W24W9.

Kallberg M, Margaryan G, Wang S, Ma J and Xu J. RaptorX server: a resource for templatebased protein structure modeling. InProtein Structure Prediction. 2014; 1137:17-27.

Kangueane P, Nilofer C. Protein-Protein Docking: Methods and Tools. InProtein-Protein and Domain-Domain Interactions. 2018:161-168.

Karplus P, Schulz G. Prediction of chain flexibility in proteins. Naturwissenschaften. 1985;72:212-3.

Kaur H, Garg A and Raghava G. PEPstr: a de novo method for tertiary structure prediction of small bioactive peptides. Protein Pept Let. 2007;14:626-31.

Kaushic C, Roth KL, Anipindi V, Xiu F. Increased prevalence of sexually transmitted viralinfections in women: the role of female sex hormones in regulating susceptibility and immune responses. J Reprod Immunol. 2011;88:204-209.

Kimberlin DW, Rouse DJ. Clinical practice: genital herpes. N Engl J Med. 2004;350: 19701977.

Koelle DM, Corey L. Recent progress in herpes simplex virus immunobiology and vaccine research. Clinical microbiology reviews. 2003;16(1):96-113.

Kolaskar A, Tongaonkar PC. A semi-empirical method for prediction of antigenic determinants on protein antigens. FEBS letters. 1990;276:172-4.

Korber B, LaBute M, Yusim K. Immunoinformatics comes of age. PLOS Comput Biol. 2006;2(6):e71.

Kosciolek T, Jones DT. De novo structure prediction of globular proteins aided by sequence variation-derived contacts. PloS one. 2014;9:e92197. 
Krogh A, Larsson B, Von Heijne G, Sonnhammer EL. Predicting transmembrane protein topology with a hidden markov model: application to complete genomes1. Journal of molecular biology. 2001;305:567-80.

Lafferty WE, Coombs RW, Benedetti J, et al. Recurrences after oral and genital herpes simplex virus infection. Influence of site of infection and viral type. $\mathrm{N}$ Engl $\mathrm{J}$ Med. 1987;316:1444-9.

Lafferty WE, Downey L, Celum C, et al. Herpes simplex virus type 1 as a cause of genital herpes: impact on surveillance and prevention. J Infect Dis. 2000;181:1454-7.

Lafferty WE, Downey L, Celum C, Wald A. Herpes simplex virus type 1 as a cause of genital herpes: impact on surveillance and prevention. J Infect Dis. 2000;181:1454-1457.

Langenberg, Andria GM, Corey L, Ashley RL, Leong WP, Strauset SE. A prospective study of new infections with herpes simplex virus type 1 and type 2. New Eng $J$ of Med. 1999;341:1432-1438.

Leoni V, Gianni T, Salvioli S, Campadelli-Fiume G. Herpes Simplex Virus Glycoproteins gH/gL and gB Bind Toll-Like Receptor 2, and Soluble gH/gL Is Sufficient To Activate NFкB. Journal of Virology. 2012;86:6555-6562.

Looker KJ, Magaret AS, May MT, et al. First estimates of the global and regional incidence of neonatal herpes infection. Lancet Glob Health. 2017;5(3):e300-e309.

Looker KJ, Magaret AS, Turner KM, Vickerman P, Gottlieb SL, Newman LM. Global estimates of prevalent and incident herpes simplex virus type 2 infections in 2012. PloS one. 2015;10(1):e114989.

Lopez-Blanco JR, Aliaga JI, Quintana-Orti ES, Chacon P. iMODS: internal coordinates normal mode analysis server. Nucleic Acids Res. 2014;42:W271-W276.

Lopez-Blanco JR, Garzon JI, Chacon P. iMod: multipurpose normal mode analysis in internal coordinates. Bioinformatics. 2011;27(20): 2843-2850. 
Lovell SC, Davis IW, Arendall WB, Bakker PIW, Word JM, Prisant MG, Richardson JS and Richardson DC Structure validation by Calpha geometry: phi, psi and Cbeta deviation. Proteins: Structure, Function \& Genetics. 2002;50:437-450.

Lowhagen GB, Tunback P, Bergstrom T. Proportion of herpes simplex virus (HSV) type 1 and type 2 among genital and extragenital HSV isolates. Acta Derm Venereol 2002;82:11820.

Macalino S, Basith S, Clavio N, Chang H, Kang S, Choi S. Evolution of In Silico Strategies for Protein-Protein Interaction Drug Discovery. Molecules. 2018;23(8):1963.

Maupetit J, Derreumaux P, Tuffery P. A fast method for large scale De Novo peptide and miniprotein structure prediction. Journal of computational chemistry. 2010;31:726-38.

McQuillan G, Kruszon-Moran D, Flagg EW, et al. Prevalence of Herpes Simplex Virus Type 1 and Type 2 in Persons Aged 14-49: United States, 2015-2016. NCHS Data Brief. 2018;304:1-8.

Mora M, Veggi D, Santini L, Pizza M, Rappuoli R. Reverse vaccinology Drug discovery today. 2003;8(10):459-64.

Morris GM, Huey R, Lindstrom W, Sanner MF, Belew RK, Goodsell DS, et al. AutoDock4 and AutoDockTools4: Automated docking with selective receptor flexibility. J Comput Chem. 2009;30:2785-91.

Nahmias AJ, Lee FK, Beckman-Nahmias S. Sero-epidemiological and - sociological patterns of herpes simplex virus infection in the world. Scand J Infect Dis Suppl. 1990;69:19-36.

Nielsen M, Lundegaard C, Blicher T, Lamberth K, Harndahl M, et al. NetMHCpan, a method for quantitative predictions of peptide binding to any HLA-A and-B locus protein of known sequence. PLOS one. 2007;2(8):e796.

Pandey RK, Sundar S, Prajapati VK. Differential expression of miRNA regulates T cell differentiation and plasticity during visceral leishmaniasis infection. Front Microbiol. 2016;7:206. 
Parker J, Guo D, Hodges R. New hydrophilicity scale derived from high-performance liquid chromatography peptide retention data: correlation of predicted surface residues with antigenicity and X-ray-derived accessible sites. Biochemistry. 1986;25:5425-32.

Patel R, Boseli F, Cairo I, Barnett G, Price M, Wulf HC. Patients' perspectives on the burden of recurrent genital herpes. Int J STD AIDS. 2001;12:640-5.

Peng J, Xu J. RaptorX: exploiting structure information for protein alignment by statistical inference. Proteins: Structure, Function and Bioinformatics. 2011;79(S10): 161-71.

Petersen B, Lundegaard C, Petersen TN. NetTurnP-neural network prediction of beta-turns by use of evolutionary information and predicted protein sequence features. PLoS One. 2010;5(11):e15079.

Prabhakar PK, Srivastava A, Rao KK, Balaji PV. Monomerization alters the dynamics of the lid region in campylobacter jejuni CstII: an MD simulation study. J Biomol Struct Dyn. 2016;34(4):778-79.

Purcell AW, McCluskey J, Rossjohn J. More than one reason to rethink the use of peptides in vaccine design Nat Rev Drug Discov. 2007;6:404-414.

Raghuwanshi, Singh R, Shukla M, Vandana. Immunoinformatic Approaches in Epitope Prediction for Vaccine Designing against Viral infections. Virology and Immunology Journal. 2018;2:000142.

Rana A, Akhter Y. A multi-subunit based, thermodynamically stable model vaccine using combined immunoinformatics and protein structure based approach. Immunobiology. 2016;221:544-557.

Rappuoli R, Bottomley MJ, D’Oro U, Finco O, De Gregorio E. Reverse vaccinology 2.0: Human immunology instructs vaccine antigen design. Journal of Experimental Medicine. 2016;213(4):469-481.

Rappuoli R. Reverse vaccinology. Curr Opin Microbiol. 2000;3:445-450. 
Reynolds SJ, Risbud AR, Shepherd ME, Zenilman JM, Brookmeyer RS, et al. Recent herpes simplex virus type 2 infection and the risk of human immunodeficiency virus type 1 acquisition in India. J Infect Dis. 2003;187:1513-1521.

Ribes JA, Steele AD, Seabolt JP, Baker DJ. Sixyear study of the incidence of herpes in genital and nongenital cultures in a central Kentucky medical center patient population. J Clin Microbiol. 2001;39:3321-3325.

Roberts CM, Pfister JR, Spear SJ. Increasing proportion of herpes simplex virus type 1 as a cause of genital herpes infection in college students. Sex Transm Dis. 2003;30:797-800.

Roberts CM, Pfister JR, Spear SJ. Increasing proportion of herpes simplex virus type 1 as a cause of genital herpes infection in college students. Sex Transm Dis. 2003;30(10):797-800.

Ryan KJ, Ray CG (editors) Sherris Medical Microbiology (4th ed.). McGraw Hill. 2004:55562.

Sabchareon A, Wallace D, Sirivichayakul C, Limkittikul K, Chanthavanich P, Suvannadabba S, Jiwariyavej V, Dulyachai W, Pengsaa K, Wartel TA, et al. Protective efficacy of the recombinant, live-attenuated, CYD tetravalent dengue vaccine in Thai schoolchildren: a randomised, controlled phase 2b trial Lancet. 2012;380:1559-1567.

Saha CK, Hasan MM, Hossain MS, Jahan MA, Azad AK. In silico identification and characterization of common epitope-based peptide vaccine for Nipah and Hendra viruses, Asian Pacific Journal of Tropical Medicine. 2017;10(6):529-538.

Saha S, Raghava GP. AlgPred: prediction of allergenic proteins and mapping of IgE epitopes. Nucleic acids research. 2006;34(suppl_2):W202-9.

Sanner MF. Python: A Programming Language for Software Integration and Development. J Mol Graph Model. 1999;17(1):57-61.

Sato A, Linehan MM, Iwasaki A. Dual recognition of herpes simplex viruses by TLR2 and TLR9 in dendritic cells. Proceedings of the National Academy of Sciences. 2006;103(46):17343-17348. 
Saxena R, Mishra G, Diwan B, Tiwari A. HIV/AIDS Vaccine Design and Strategies. J Vaccines Vaccin. 2013; 4:190.

Schneidman-Duhovny D, Inbar Y, Nussinov R, Wolfson HJ. PatchDock and SymmDock: servers for rigid and symmetric docking. Nucl Acids Res. 2005;33:W363-7.

Scoular A, Norrie J, Gillespie G, et al. Longitudinal study of genital infection by herpes simplex virus type 1 in Western Scotland over 15 years. BMJ. 2002;324:1366.

Shrestha B. Role of CD8+ T cells in control of West Nile virus infection. J Virol. 2004;12:8312-21.

Skoberne M, Cardin R, Lee A, et al. An adjuvanted herpes simplex virus 2 subunit vaccine elicits a $\mathrm{T}$ cell response in mice and is an effective therapeutic vaccine in Guinea pigs. $\mathrm{J}$ Virol. 2013;87(7):3930-42.

Solanki V, Tiwari V. Subtractive proteomics to identify novel drug targets and reverse vaccinology for the development of chimeric vaccine against Acinetobacter baumannii. Scientific reports. 2018;8(1):9044.

Stanberry LR, Jorgensen DM, Nahmias AJ. Herpes simplex viruses 1 and 2. In: Evans AS, Kaslow R, eds. Viral Infections of Humans: Epidemiology and Control. 4th ed. New York, NY: Plenum Publishers. 1997:419-454.

Stanberry LR, Jorgensen DM, Nahmias AJ. Herpes simplex viruses 1 and 2. In: Evans AS, Kaslow R, eds. Viral Infections of Humans: Epidemiology and Control. 4th ed. New York, NY: Plenum Publishers. 1997:419-454

Strutt M, Bailey J, Tenant-Flowers M, et al. Ethnic variation in type of genital herpes simplex virus infection in a South London genitourinary medicine clinic. J Med Virol. 2003;69:10810.

Tama F, Brooks CL. Symmetry, form, and shape: guiding principles for robustness in macromolecular machines. Annu Rev Biophys Biomol Struct. 2006;35:115-33. 
Tameris MD, Hatherill M, Landry BS, Scriba TJ, Snowden MA, et al. Safety and efficacy of MVA85A, a new tuberculosis vaccine, in infants previously vaccinated with BCG: a randomised, placebo-controlled phase 2b trial Lancet. 2013;381:1021-1028.

Thaysen-Andersen M, Packer NH. Site-specific glycoproteomics confirms that protein structure dictates formation of N-glycan type, core fucosylation and branching. Glycobiology. 2012;22(11):1440-52.

Veselenak RL, Shlapobersky M, Pyles RB, et al. A Vaxfectin®-adjuvanted HSV-2 plasmid DNA vaccine is effective for prophylactic and therapeutic use in the guinea pig model of genital herpes. Vaccine. 2012;30(49):7046-51.

Vita R, Overton JA, Greenbaum JA, Ponomarenko J, Clark JD, Cantrell JR, et al. The immune epitope database (IEDB) 3.0. Nucleic acids research. 2014;43:D405-D12.

Whitley R, Baines J. Clinical management of herpes simplex virus infections: past, present, and future. F1000 Research. 2018;7(F1000 Faculty Rev):1726

Wong SS, Jeevan T, Kercher L, Yoon SW, Petkova AM, Crumpton JC, et al. A single dose of whole inactivated H7N9 influenza vaccine confers protection from severe disease but not infection in ferrets. Vaccine. 2014;32:4571-7.

Wuthrich K, Wagner G, Rene Richarz, and Werner Braun. Correlations between internal mobility and stability of globular proteins, Biophys J. 1980:549-558.

Xu D, Zhang Y. Improving the Physical Realism and Structural Accuracy of Protein Models by a Two-step Atomic-level Energy Minimization. Biophysical Journal. 2011;101:2525-2534.

Xu F, Sternberg MR, Kottiri BJ, et al. Trends in herpes simplex virus type 1 and type 2 seroprevalence in the United States. JAMA. 2006;296:964-73.

Yang X, Yu X. An introduction to epitope prediction methods and software. Rev Med Virol. 2009;19(2):77-96.

Yang Y, Sun W, Guo J, Zhao G, Sun S, Yu H, et al. In silico design of a DNA-based HIV-1 multi-epitope vaccine for Chinese populations. Human Vaccines \& Immunotherapeutics. 2015;11:795-805. 
Yang Y, Sun W, Guo J, Zhao G, Sun S, Yu H, Guo Y, Li J, Jin X, Du L, Jiang S, Kou Z, Zhou Y. In silico design of a DNA-based HIV-1 multi-epitope vaccine for Chinese populations. Hum Vaccin Immunother. 2015:11(3):795-805.

Zhang J, Liang Y, Zhang Y. Atomic-Level Protein Structure Refinement Using FragmentGuided Molecular Dynamics Conformation Sampling. Structure 2011;19:1784-1795.

Tables

Table 1. Highly antigenic conserved regions identified among different sets of HSV proteins.

\begin{tabular}{|c|l|c|c|}
\hline Proteins & \multicolumn{1}{|c|}{ Conserved regions } & Vaxijen score & Topology \\
\hline \multirow{5}{*}{ GP B39 } & NATVAAGHATLR & 0.9230 & Inside \\
\cline { 2 - 4 } & $\begin{array}{l}\text { HLREIKVENADAQFYVCPPPTGATVVQFEQPRRCPTRP } \\
\text { EGQNYTEGIAVVFKENIAPYKFKATMYYKDVTVSQVW }\end{array}$ & 0.5011 & Outside \\
\cline { 2 - 4 } & FGHRYSQFMGIFEDRAPVPFEEVIDKIN & & Inside \\
\cline { 2 - 5 } & ETTAFHRDDHETDMELKPA & 0.9516 & Inside \\
\cline { 2 - 4 } & ATRTSRGWHTTDLKYNPSRVEAFHRYGTTV & 0.7251 & \multicolumn{1}{|c|}{. } \\
\hline
\end{tabular}




\begin{tabular}{|c|c|c|c|}
\hline & CIVEEVDARSVYPY & 0.6854 & Inside \\
\hline & $\begin{array}{l}\text { EFVLATGDFVYMSPFYGYREGSHTEHTSYAADRFKQV } \\
\text { DGFYARDLTTKA }\end{array}$ & 0.5531 & Outside \\
\hline & PTTRNLLTTPKFTVAWDWVPKRP & 0.5059 & Outside \\
\hline & GGSFRFSSDAISTTFTTNLT & 0.4575 & Outside \\
\hline & LSRVDLGDCIGRDAR & 0.6069 & Inside \\
\hline & YNATHIKVGQPQYYLA & 0.8046 & Inside \\
\hline & SANASVERIKTTSSIEFARLQFTYNHIQRHVNDMLGR & 0.4695 & Inside \\
\hline & AWCELQNHELTLWNEARKLNPN & 0.4741 & Outside \\
\hline & $\begin{array}{l}\text { DNVIVQNSMRVSSRPGTCYSRPLVSFRYEDQGPLIEGQL } \\
\text { GENNELRLTRDALEPCTVGHRRYF }\end{array}$ & 0.6431 & Inside \\
\hline & AYSHQLSRAD & 0.4487 & Inside \\
\hline & TFIDLNITMLEDHEFVPL & 1.4769 & Outside \\
\hline & $\begin{array}{l}\text { VYTRHEIKDSGLLDYTEVQRRNQLHDLRFADIDTVIRA } \\
\text { DANAAMFAGL }\end{array}$ & 0.8983 & Inside \\
\hline & $\begin{array}{l}\text { AFFEGMGDLGRAVGKVVMGVVGGVVSAVSGVSSFMS } \\
\text { NPFGALAVGLLVLAGL }\end{array}$ & 0.4125 & Inside \\
\hline & AAFFAFRYVLQLQ & 0.9324 & Outside \\
\hline & NPMKALYPLTTKE & 0.7995 & Outside \\
\hline & MERTEHKARKKGTSALLSSKVTNMVLRKR & 0.9460 & Inside \\
\hline \multirow{9}{*}{ GP C } & MAPGRVGLAVVLWSLLWLGAGVAGG & 0.8581 & Outside \\
\hline & ASTGPTITAGAVTNAS & 0.7173 & Outside \\
\hline & NKTTPTEPASPPTTPKPTSTPKSPP & 0.5363 & Inside \\
\hline & CNRHDPLARYGSR & 0.6576 & Inside \\
\hline & TQTQENPDGFSTVSTVTS & 0.6449 & Inside \\
\hline & FSRRNASG & 0.6593 & Inside \\
\hline & ATIRSTLPVSYE & 0.8098 & Inside \\
\hline & TEYICRLAGYP & 0.6823 & Inside \\
\hline & TAVVYLTHAS & 0.8776 & Inside \\
\hline \multirow{3}{*}{ GP D } & $\begin{array}{l}\text { MGRLTSGVGTAALLVVAVGLRVVCAKYALADPSLKMA } \\
\text { DPNRFRGKNLPVLDQLTDPPGVKRVYHIQPSLE }\end{array}$ & 0.6946 & Outside \\
\hline & YNLTIAWYRMGNCAIPITVMEYTEC & 0.7924 & Inside \\
\hline & CPIRTQPRW & 1.7378 & Inside \\
\hline
\end{tabular}




\begin{tabular}{|c|c|c|c|}
\hline & SCKYALPLRIPPAACLT & 0.4252 & Outside \\
\hline & PENQRTVALYSLKIAGWHGPK & 0.4048 & Inside \\
\hline & PYTSTLLPPELSDT & 0.8452 & Outside \\
\hline & QIPPNWHIPSIQD & 0.9706 & Outside \\
\hline & PYHPPATPNNMGLIAGAVGGSLLAALVI & 0.5960 & Outside \\
\hline & RLPHIRDDD & 1.0727 & Inside \\
\hline \multirow{8}{*}{ GP E } & WVSLMPPKQV & 1.0419 & Outside \\
\hline & ETVVDAACMRAP & 0.4371 & Inside \\
\hline & PLAMAYAPP & 0.7544 & Outside \\
\hline & ARQVASVVLVVQP & 0.6373 & Inside \\
\hline & PEVSHVRGVTVRMET & 0.4485 & Inside \\
\hline & RLAVRSYAGC & 0.7672 & Inside \\
\hline & WACMTCWRRRAWRAVKSRAS & 0.4673 & Inside \\
\hline & LTTFGSGSP & 0.5172 & Outside \\
\hline \multirow{11}{*}{ GP G } & $\begin{array}{l}\text { MHAIAPRLLLLFVLSGLPGTRGGSGVPGPINPPNNDVV } \\
\text { FPGGSPVAQYCYAYPRLDDPGPLGSADAGRQD }\end{array}$ & 0.5000 & Outside \\
\hline & ARVTYYRLTRACR & 0.4072 & Inside \\
\hline & GELHVGLLWVEVGGEGPG & 0.6943 & Outside \\
\hline & $\begin{array}{l}\text { AEGGPCVPPVPAGRPWRSVPPVWYSAPNPGFRGLRFRE } \\
\text { RCLPPQTPAAPSDLPRVAFAPQSLLVGITGRTFIRMARPT }\end{array}$ & 0.8478 & Outside \\
\hline & DVGVLPPHWAPGAL & 1.3344 & Outside \\
\hline & GVDPDVRAPRTGRRLMALTE & 0.6235 & Inside \\
\hline & SSDSPTSAPEKTPLPVSATAMAPSVDPSAEPTAP & 0.5028 & Outside \\
\hline & QAATVAVTP & 1.0952 & Inside \\
\hline & ETAVASPPATASVESSPLP & 0.6367 & Outside \\
\hline & $\begin{array}{l}\text { AAAATPGAGHTNTSSASAAKTPPTTPAPTTPPPTSTHAT } \\
\text { PRPTTPGPQTTPPGPATPGPVGASAAPTADSPLTASPPAT } \\
\text { APGPSAANVSVAATTATPGTRGTARTPPTDPKTHPHGPA } \\
\text { DAPPGSPAPPPPEHRGGPEEFEGAGDGEPPEDDDSATGL } \\
\text { AFRTPNPNKPPPARPGPIRPTLPPGILGPLAPNTP }\end{array}$ & 0.4306 & Outside \\
\hline & $\begin{array}{l}\text { QAPAKDMPSGPTPQHIPLFWFLTASPALDILFIISTTIHTA } \\
\text { AFVCLVALAAQLWRGRAGRRRYAHPSVRYVCLPPERD }\end{array}$ & 0.6777 & Outside \\
\hline Envelope & WDPTPMEHEQAVGGC & 0.8783 & Outside \\
\hline
\end{tabular}




\begin{tabular}{|c|l|c|c|}
\hline $\begin{array}{c}\text { protein } \\
\text { UL45 }\end{array}$ & APATLIPRAAAK & 0.5466 & Inside \\
\hline
\end{tabular}

Table 2. Predicted CTL epitopes among HSV proteins to construct multiepitope polyvalent vaccine.

\begin{tabular}{|c|c|c|c|c|}
\hline Proteins & $\begin{array}{c}\text { Top CTL } \\
\text { Epitopes }\end{array}$ & Interacting MHC I Molecules & Allergenicity & $\begin{array}{c}\text { VaxiJen } \\
\text { Score }\end{array}$ \\
\hline GP B39 & GLAAFFAFR & $\begin{array}{c}\text { HLA-A*31:01, HLA-A*68:01, HLA-A*33:01, } \\
\text { HLA-A*11:01, HLA-A } * 3: 01\end{array}$ & Non Allergen & 0.8634 \\
\hline GP C & SLLWLGAGV & HLA-A*02:01, HLA-A*02:03, HLA-A*02:06 & Non Allergen & 1.1557 \\
\hline GP D & LLAALVIRL & HLA-A*02:03, HLA-A*02:01, HLA-A*02:06 & Non Allergen & 0.8730 \\
\hline GP E & KQVPLAMAY & HLA-B*15:01, HLA-A*02:06, HLA-A*30:02 & Non Allergen & 0.9020 \\
\hline GP G & HTAAFVCLV & HLA-A*02:06, HLA-A*68:02, HLA-A*02:03 & Non Allergen & 1.1073 \\
\hline Envelope & HEQAVGGCW & HLA-A*11:01, HLA-B*44:02, HLA-B*44:03 & Non Allergen & 0.6080 \\
\hline Protein UL45 & & & & \\
\hline
\end{tabular}


Table 3. Predicted HTL epitopes among HSV proteins to be a part of multiepitope polyvalent vaccine.

\begin{tabular}{|c|c|c|c|c|}
\hline Proteins & Top HTL Epitopes & Interacting MHC II Molecules & Allergenicity & $\begin{array}{c}\text { VaxiJen } \\
\text { Score }\end{array}$ \\
\hline GP B39 & NPFGALAVGLLVLAG & $\begin{array}{l}\text { HLA-DRB1*01:01, HLA-DQA1*05:01, } \\
\text { HLA-DRB1*09:01, } \\
\text { HLA-DPA1*03:01/DPB1*04:02 }\end{array}$ & Non Allergen & 0.8490 \\
\hline GP C & RVGLAVVLWSLLWLG & $\begin{array}{c}\text { HLA-DPA } 1 * 03: 01 / \text { DPB } 1 * 04: 02, \\
\text { HLA-DPA } 1 * 02: 01 / D P B 1 * 01: 01, \\
\text { HLA-DPA } 1 * 01: 03 / D P B 1 * 02: 01, \\
\text { HLA-DRB } 1 * 01: 01, \text { HLA-DRB } 4 * 01: 01, \\
\text { HLA-DRB } 1 * 15: 01, \text { HLA-DRB } 1 * 07: 01, \\
\text { HLA-DRB } 1 * 04: 05\end{array}$ & Non Allergen & 0.7390 \\
\hline GP D & AALLVVAVGLRVVCA & $\begin{array}{l}\text { HLA-DRB } 1 * 07: 01, \text { HLA-DRB } 1 * 01: 01 \\
\text { HLA-DRB } 5 * 01: 01, \text { HLA-DRB } 1 * 09: 01 \\
\text { HLA-DRB } 1 * 13: 02, \text { HLA-DQA } 1 * 05: 01\end{array}$ & Non Allergen & 1.2353 \\
\hline
\end{tabular}




\begin{tabular}{|c|c|c|c|c|}
\hline & & HLA- DQB1 $1 * 6: 0$, HLA-DRB1*15:01 & & \\
\hline GP E & $\begin{array}{l}\text { No potential fragments } \\
\text { found with } 15 \text { residues }\end{array}$ & - & - & - \\
\hline GP G & ALDILFIISTTIHTA & $\begin{array}{l}\text { HLA-DRB } 1 * 07: 01, \text { HLA-DRB1*01:01, } \\
\text { HLA-DRB } 1 * 15: 01, \text { HLA-DRB } 1 * 04: 01, \\
\text { HLA-DRB } 1 * 13: 02, \text { HLA-DRB } 1 * 11: 01, \\
\text { HLA-DRB } 1 * 04: 05, \text { HLA-DRB5 } * 01: 01, \\
\text { HLA-DQA } 1 * 01: 02 / D Q B 1 * 06: 02, \\
\text { HLA-DRB4*01:01, HLA-DPA1*02:01 }\end{array}$ & Non Allergen & 0.8169 \\
\hline $\begin{array}{c}\text { Envelope } \\
\text { Protein } \\
\text { UL45 }\end{array}$ & HLAALARVQAERSSG & $\begin{array}{c}\text { HLA-DRB } 1 * 01: 01, \text { HLA- } \\
\text { DQA1*03:01,HLA-DRB3*01:01, HLA- } \\
\text { DRB1 } * 08: 02, \\
\text { HLA-DRB1 } * 04: 01, \text { HLA-DRB } 1 * 11: 01\end{array}$ & Non Allergen & 0.5567 \\
\hline
\end{tabular}

Table 4. Binding energy of suggested T-cell epitopes with selected MHC class I and class-II molecules generated from molecular docking analysis.

\begin{tabular}{|c|c|c|c|c|c|c|}
\hline Proteins & Epitopes & MHC alleles & $\begin{array}{c}\text { Binding } \\
\text { energy } \\
\text { (kcal/mol) }\end{array}$ & Epitopes & MHC alleles & $\begin{array}{c}\text { Binding } \\
\text { energy } \\
\text { (kcal/mol) }\end{array}$ \\
\hline GP B39 & GLAAFFAFR & HLA-A*11:01 & -6.4 & NPFGALAVGLLVLAG & \multirow{6}{*}{$\begin{array}{c}\text { HLA- } \\
\text { DRB1*01:01 }\end{array}$} & -5.3 \\
\hline GPC & SLLWLGAGV & \multirow{4}{*}{ HLA-A*02:06 } & -5.6 & RVGLAVVLWSLLWLG & & -8.3 \\
\hline GP D & LLAALVIRL & & -5.9 & AALLVVAVGLRVVCA & & -6.6 \\
\hline GP E & KQVPLAMAY & & -3.0 & - & & - \\
\hline GP G & HTAAFVCLV & & -7.0 & ALDILFIISTTIHTA & & -6.2 \\
\hline $\begin{array}{c}\text { Envelope } \\
\text { Protein } \\
\text { UL45 }\end{array}$ & HEQAVGGCW & HLA-A*11:01 & -6.2 & HLAALARVQAERSSG & & -5.6 \\
\hline
\end{tabular}


Table 5. Predicted B cell epitopes among HSV proteins to design multiepitope polyvalent vaccine.

\begin{tabular}{|c|c|c|c|}
\hline Proteins & Top BCL Epitopes & Allergenicity & $\begin{array}{c}\text { Antigenicity (VaxiJen } \\
\text { Score) }\end{array}$ \\
\hline GP B39 & PTGATVVQFE & Non Allergen & 1.19 \\
\hline GP C & MAPGRVGLAV & Non Allergen & 1.42 \\
\hline GP D & VKRVYHIQPS & Non Allergen & 1.17 \\
\hline GP E & PKQVPLAMAY & Non Allergen & 1.34 \\
\hline GP G & AFAPQSLLVG & Non Allergen & 1.13 \\
\hline GP UL45 & WDPTPMEHEQ & Non Allergen & 1.64 \\
\hline
\end{tabular}

Table 6. Allergenicity and antigenicity analysis of the constructed vaccines.

\begin{tabular}{|c|c|c|c|c|}
\hline $\begin{array}{c}\text { Vaccine } \\
\text { Constructs }\end{array}$ & Composition & Complete Sequence of Vaccine Constructs & Allergenicity & $\begin{array}{l}\text { VaxiJen score } \\
\text { (Threshold 0.4) }\end{array}$ \\
\hline V1 & $\begin{array}{l}\text { Predicted top CTL, } \\
\text { HTL \& BCL } \\
\text { epitopes of HSV } \\
\text { glycoproteins with } \\
\beta \text { defensin adjuvant } \\
\& \quad \text { PADRE } \\
\text { sequence }\end{array}$ & $\begin{array}{l}\text { EAAAKGIINTLQKYYCRVRGGRCAVLSCLPKEEQI } \\
\text { GKCSTRGRKCCRRKKEAAAKAKFVAAWTLKAAA } \\
\text { GGGSGLAAFFAFRGGGSHEQAVGGCWGGGSSLL } \\
\text { WLGAGVGGGSLLAALVIRLGGGSKQVPLAMAYG } \\
\text { GGSHTAAFVCLVGPGPGNPFGALAVGLLVLAGGP } \\
\text { GPGHLAALARVQAERSSGGPGPGRVGLAVVLWSL } \\
\text { LWLGGPGPGAALLVVAVGLRVVCAGPGPGALDIL } \\
\text { FIISTTIHTAKKPTGATVVQFEKKWDPTPMEHEQK } \\
\text { KMAPGRVGLAVKKVKRVYHIQPSKKPKQVPLAM } \\
\text { AYKKAFAPQSLLVGKKAKFVAALKAAAGGGS }\end{array}$ & Non Allergen & 0.6488 \\
\hline
\end{tabular}




\begin{tabular}{|c|c|c|c|c|}
\hline V2 & $\begin{array}{l}\text { Predicted top CTL, } \\
\text { HTL \& BCL } \\
\text { epitopes of HSV } \\
\text { glycoproteins with } \\
\text { L7/L12 ribosomal } \\
\text { protein adjuvant \& } \\
\text { PADRE sequence }\end{array}$ & $\begin{array}{l}\text { EAAAKMAKLSTDELLDAFKEMTLLELSDFVKKFE } \\
\text { ETFEVTAAAPVAVAAAGAAPAGAAVEAAEEQSEF } \\
\text { DVILEAAGDKKIGVIKVVREIVSGLGLKEAKDLVD } \\
\text { GAPKPLLEKVAKEAADEAKAKLEAAGATVTVKEA } \\
\text { AAKAKFVAAWTLKAAAGGGSGLAAFFAFRGGGS } \\
\text { HEQAVGGCWGGGSSLLWLGAGVGGGSLLAALVI } \\
\text { RLGGGSKQVPLAMAYGGGSHTAAFVCLVGPGPG } \\
\text { NPFGALAVGLLVLAGGPGPGHLAALARVQAERSS } \\
\text { GGPGPGRVGLAVVLWSLLWLGGPGPGAALLVVAV } \\
\text { GLRVVCAGPGPGALDILFIISTTIHTAKKPTGATVV } \\
\text { QFEKKWDPTPMEHEQKKMAPGRVGLAVKKVKRV } \\
\text { YHIQPSKKPKQVPLAMAYKKAFAPQSLLVGKKAKF } \\
\text { VAAWTLKAAAGGGS }\end{array}$ & Non Allergen & 0.5834 \\
\hline V3 & $\begin{array}{l}\text { Predicted top CTL, } \\
\text { HTL \& BCL } \\
\text { epitopes of HSV } \\
\text { glycoproteins with } \\
\text { HABA adjuvant \& } \\
\text { PADRE sequence }\end{array}$ & $\begin{array}{l}\text { EAAAKMAENPNIDDLPAPLLAALGAADLALATVN } \\
\text { DLIANLRERAEETRAETRTRVEERRARLTKFQEDLP } \\
\text { EQFIELRDKFTTEELRKAAEGYLEAATNRYNELVE } \\
\text { RGEAALQRLRSQTAFEDASARAEGYVDQAVELTQ } \\
\text { EALGTVASQTRAVGERAAKLVGIELEAAAKAKFV } \\
\text { AAWTLKAAAGGGSVVHEQAVGGCWGGGSSLLW } \\
\text { LGAGVGGGSLLAALVIRLGGGSKQVPLAMAYGG } \\
\text { GSHTAAFVCLVGPGPGNPFGALAVGLLVLAGGPG } \\
\text { PGHLAALARVQAERSSGGPGPGRVGLAVVLWSLL } \\
\text { WLGGPGPGAALLVVAVGLRVVCAGPGPGALDILF } \\
\text { IISTTIHTAKKPTGATVVQFEKKWDPTPMEHEQKK } \\
\text { MAPGRVGLAVKKVKRVYHIQPSKKPKQVPLAMAY } \\
\text { KKAFAPQSLLVGKKAKFVAAWTLKAAAGGGS }\end{array}$ & Non Allergen & 0.6130 \\
\hline
\end{tabular}

Table 7. Docking score of vaccine construct V1 with different HLA alleles including HLADRB1*03:01 (1A6A), HLA-DRB5*01:01 (1H15), HLA-DRB1*01:01 (2FSE), HLADRB3*01:01 (2Q6W), HLA-DRB1*04:01 (2SEB) and HLA-DRB3*02:02 (3C5J).

\begin{tabular}{|c|c|c|c|c|c|c|}
\hline $\begin{array}{c}\text { Vaccine } \\
\text { Construct }\end{array}$ & $\begin{array}{c}\text { PDB ID of the } \\
\text { HLA Alleles }\end{array}$ & $\begin{array}{c}\text { Global } \\
\text { Energy }\end{array}$ & $\begin{array}{c}\text { Hydrogen } \\
\text { Bond Energy }\end{array}$ & ACE & Score & Area \\
\hline \multirow{2}{*}{ V1 } & 1 A6A & -5.82 & -0.72 & -1.98 & 18512 & 2711.50 \\
\cline { 2 - 7 } & $1 \mathrm{H} 15$ & -30.90 & -2.12 & 2.21 & 17326 & 3058.70 \\
\cline { 2 - 7 } & 2FSE & -14.82 & -2.77 & 10.36 & 20514 & 3143.30 \\
\hline
\end{tabular}




\begin{tabular}{|c|c|c|c|c|c|c|}
\hline & 2Q6W & -11.23 & -5.51 & 13.88 & 20570 & 3182.00 \\
\cline { 2 - 7 } & 2SEB & -48.53 & -0.51 & -2.95 & 19406 & 3194.20 \\
\cline { 2 - 7 } & 3C5J & -12.00 & -1.17 & 2.42 & 17438 & 2699.60 \\
\hline
\end{tabular}

\section{Figure captions}

Figure 1. Flow chart summarizing the protocols for the prediction of epitope based vaccine candidate by in silico reverse vaccinology technique.

Figure 2. Population coverage analysis of HSV glycoproteins.

Figure 3. Docking of predicted GP B39 epitope 'GLAAFFAFR' to HLA-A*11:01 and GP G epitope 'HTAAFVCLV' to HLA-A*02:06 with a binding energy of $-6.4 \mathrm{Kcal} / \mathrm{mol}$ and -7.0 $\mathrm{Kcal} / \mathrm{mol}$, respectively.

Figure 4. Docking of predicted GP C epitope 'RVGLAVVLWSLLWLG' and GP D epitope 'AALLVVAVGLRVVCA' to HLA-DRB $1 * 01: 01$ with a binding energy of $-8.3 \mathrm{Kcal} / \mathrm{mol}$ and $6.6 \mathrm{Kcal} / \mathrm{mol}$, respectively.

Figure 5. Secondary structure prediction of designed vaccine V1 using PESIPRED server

Figure 6. Tertiary structure prediction (A) and validation of the $3 \mathrm{D}$ structure of vaccine protein V1 through Ramachandran plot analysis (B).

Figure 7. 3D modelled structure of vaccine protein V2 (A) and V3 (B) generated via RaptorX server.

Figure 8. Disulfide engineering of vaccine protein V1; (A) Initial form, (B) Mutant form.

Figure 9. Docked complex of vaccine construct V1 with human TLR2; (A) Cartoon format and (B) Ball structure.

Figure 10: Molecular dynamics simulation of vaccine protein V1-TLR2 complex; stability of the protein-protein complex was investigated through B-factor values (A), deformability (B), variance $(C)$, eigenvalue $(D)$, covariance of residue index (E) and elastic network (F) analysis. 
Figure 11. Restriction digestion (A) and in silico cloning (B) of the gene sequence of final vaccine construct V1 into pET28a(+) expression vector. Target sequence was inserted between XhoI and EcoRI. 


\section{Sequence retrieval of 6 glycoproteins from Type-1 HSV}

BLASTp to identify the homologous protein set ( $>90 \%$ identity) for each sequence belonging to Type- 1 and Type- $2 \mathrm{HSV}$

Multiple sequence alignment to identify the common regions

Transmembrane topology screening and \& antigenicity analysis of the conserved fragments

T-Cell epitope prediction from the highly immunogenic fragments

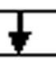

Allergenicity assessment of T-cell epitopes

Population coverage and conservancy analvsis

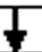

Prediction of the $3 \mathrm{~d}$ structure of the epitope using PEP-FOLD

Molecular docking analysis of HLA molecules and proposed epitopes
B-Cell epitope prediction from the aligned sequences using IEDB tools

- Bepipred linear epitope

- Emini sroface accessibility

- Chou and Fasman beta-tron prediction

- Karplus and Schulz flexibility

Vaccine construction against HSV Type- 1 and Type- 2 using proposed epitopes, adjuvants, PADRE sequence and appropriate linkers

Allergenicity and antigenicity prediction of designed vaccine constructs

Physicochemical characterization and secondary structure analysis

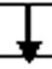

Tertiary structure prediction, re? nement and validation

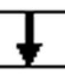

Protein-protein docking and molecular dynamics simulation

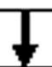




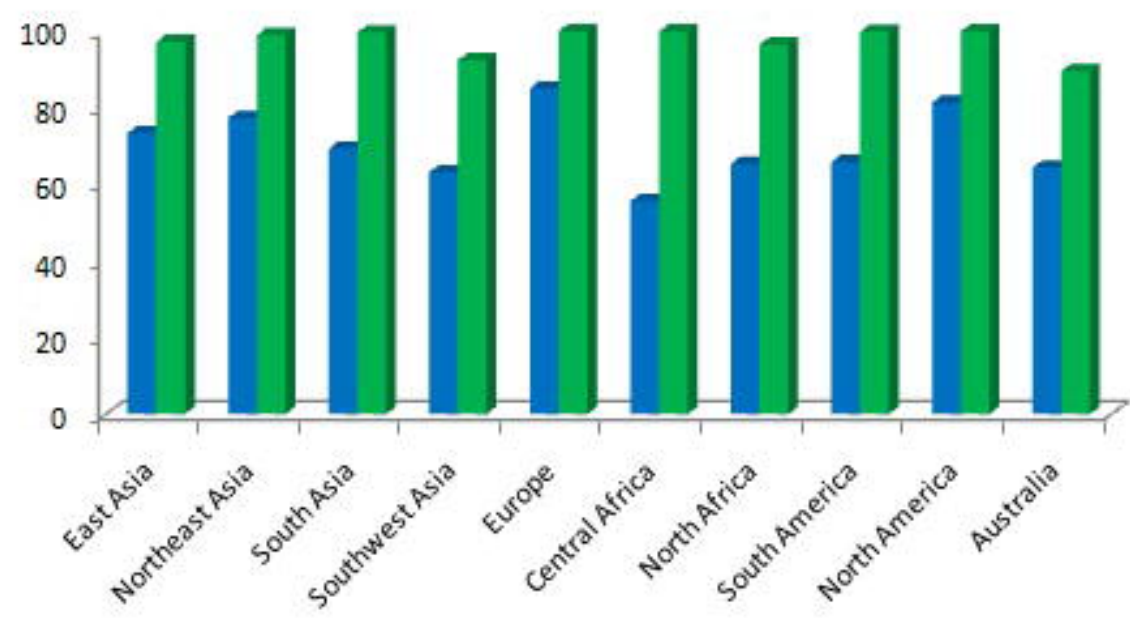

- MHC-I coverage (\%) = MHC-II coverage $(\%)$ 


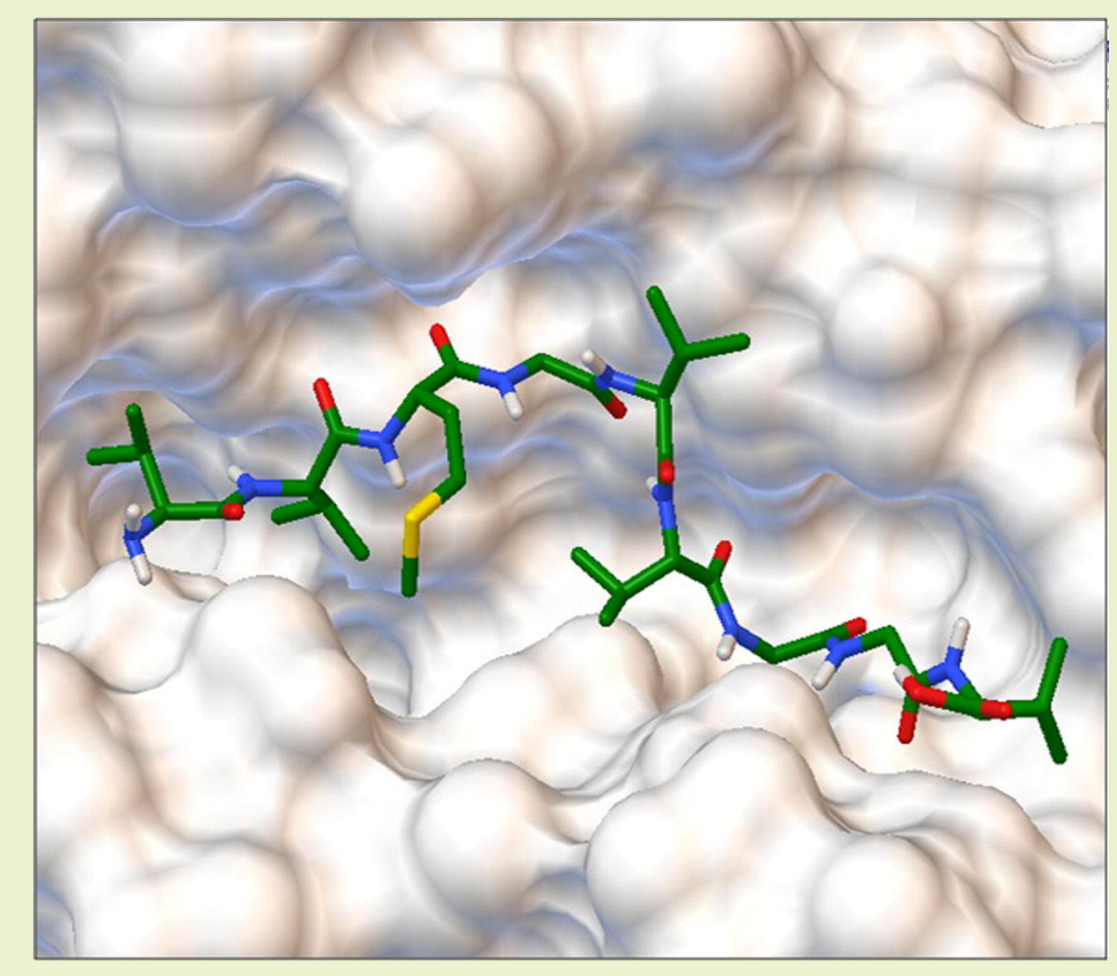

A

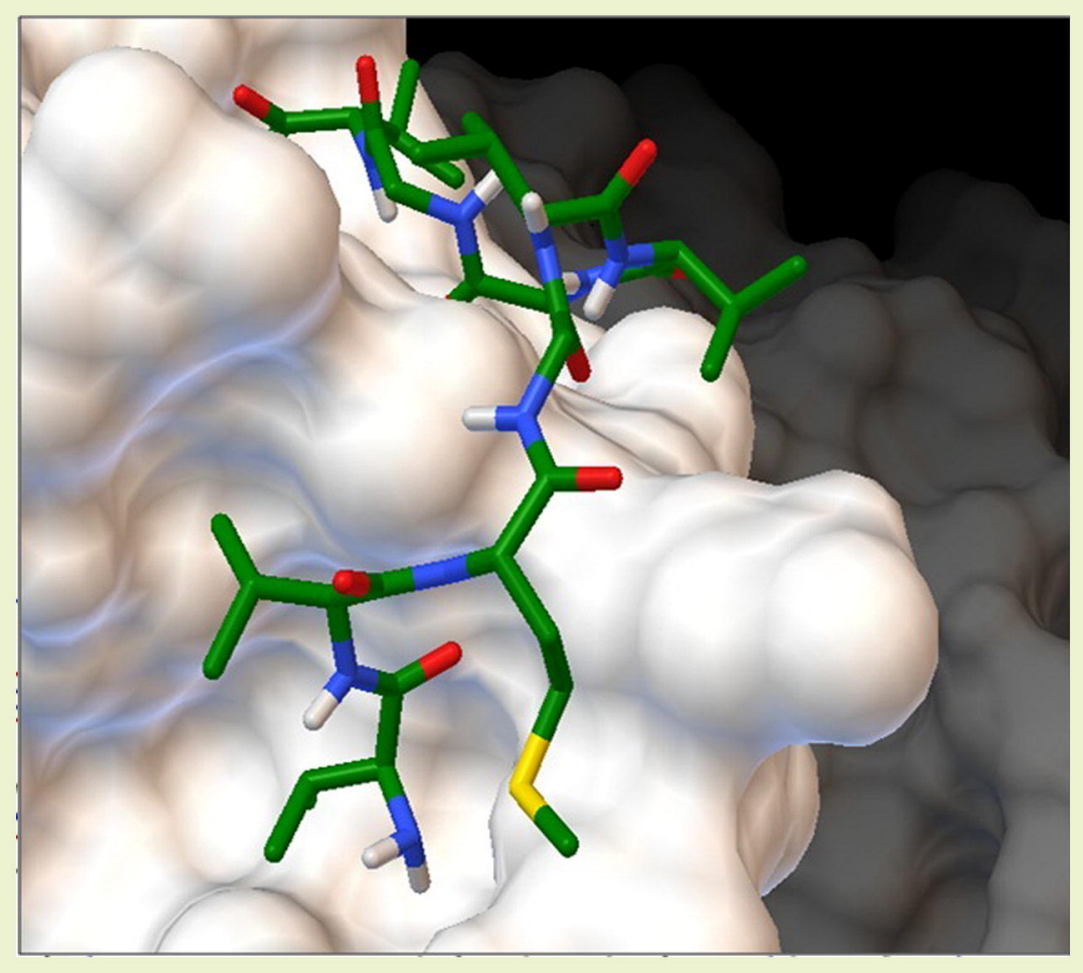

B 


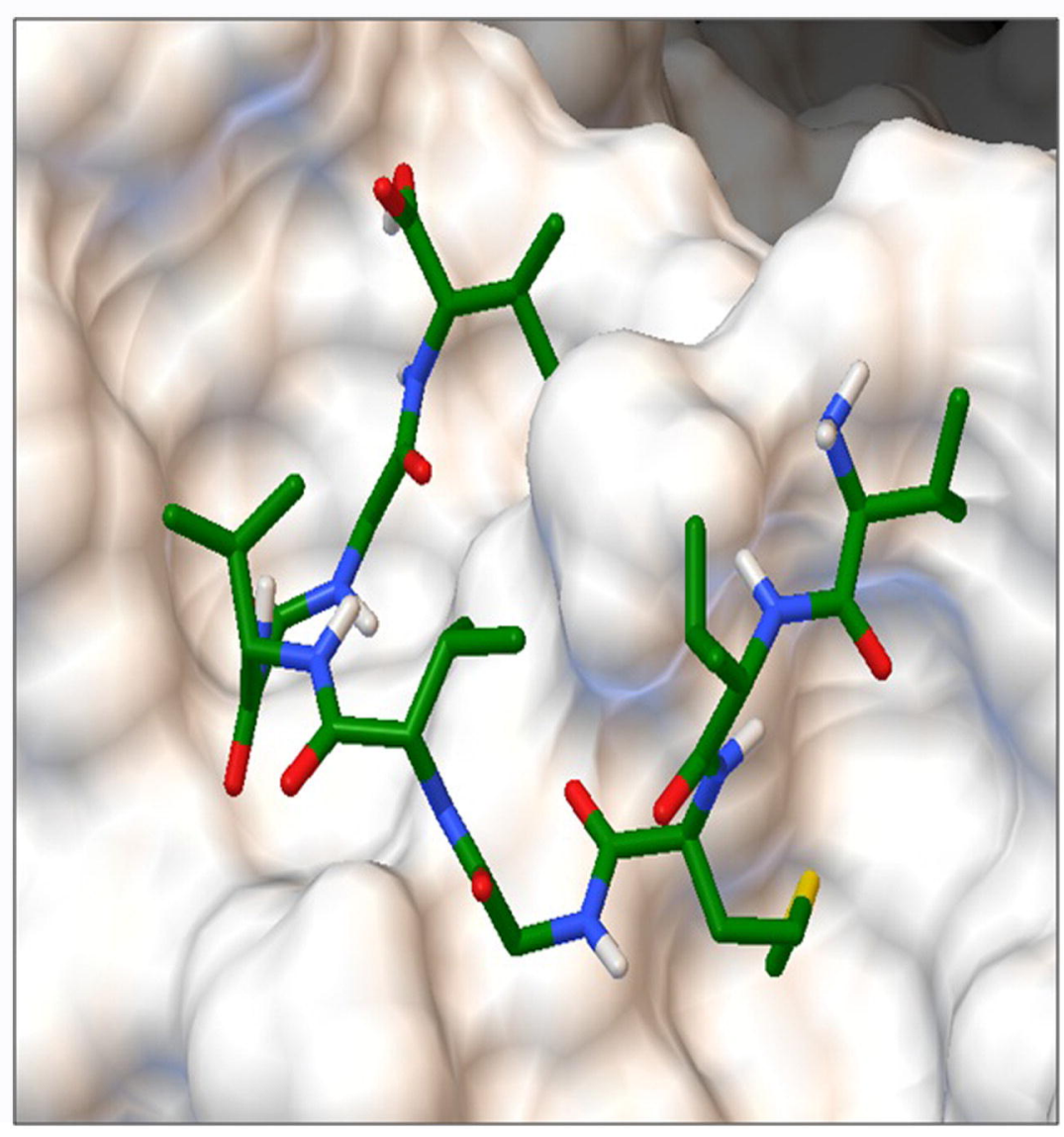

A

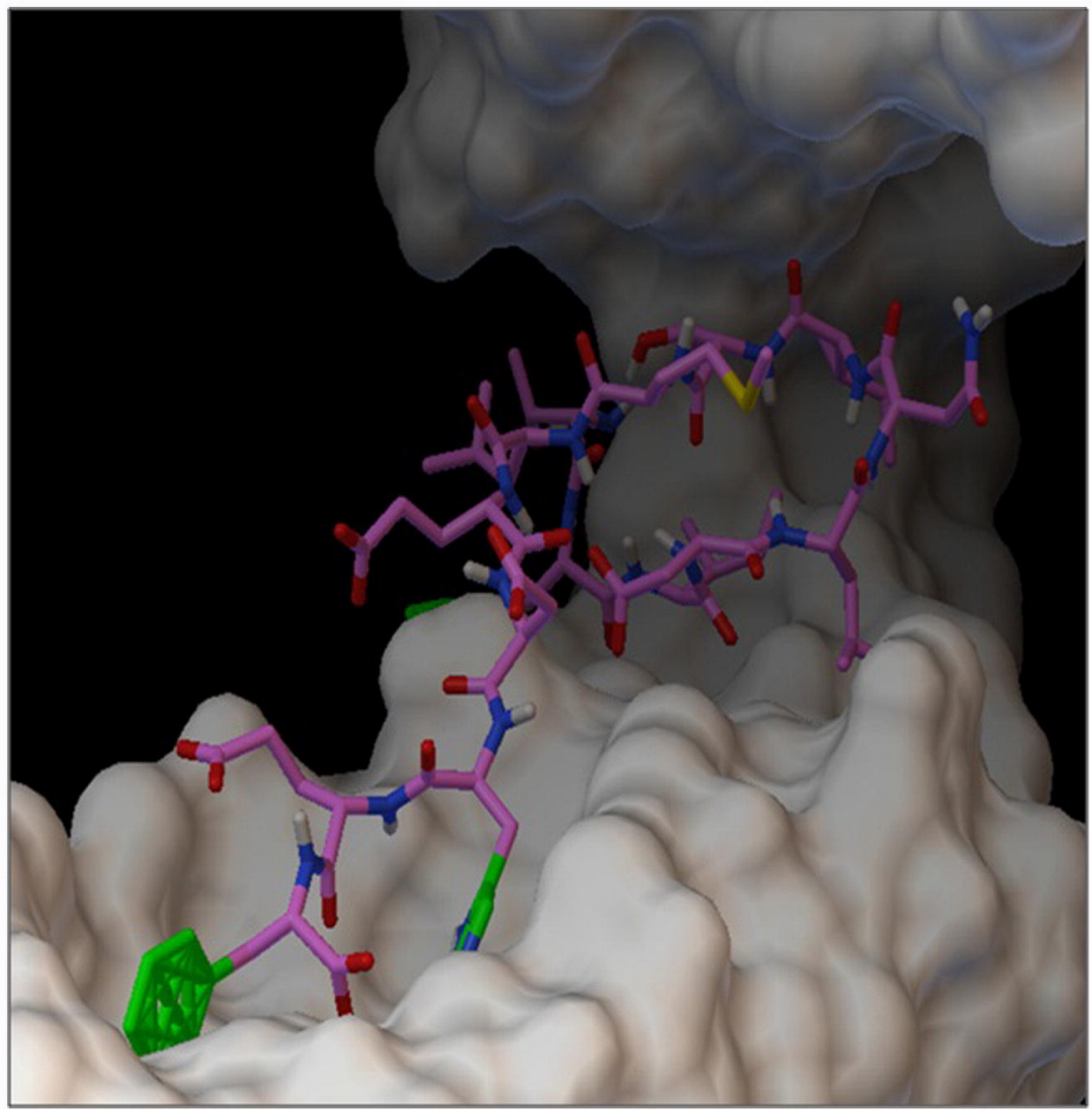

B 


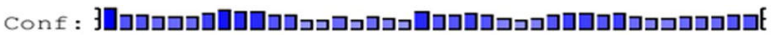

Pred:

Pred: CCCCCCHHHHHHHHEEEECCCEEEEECCCCCCCCCCCCCC AA: EAAAKGI INTLQKYYCRVRGGRCAVLSCLPKEEQIGKCST $\begin{array}{lll}10 & 20 & 30\end{array}$

Conf : \} \} Pred:

Pred: CCCHнннсCCCHннннннннннннннн CCCCCCCEEEEE AA: RGRKCCRRKKEAAAKAKEVAAWTLKAAAGGGSGLAAFFAF
50
60
70
80

Conf : \} Pred:

Pred: CCCCCCCCCCCCCCCCCCCCEEECCCCCCHнHнннНнНH AA: RGGGSHEQAVGGCWGGGSSLLWLGAGVGGGSLLAALVIRL 90 100

110 120

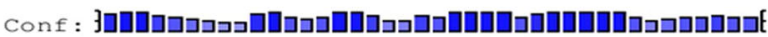
Pred: Pred:
A.A :

CCCCCCCCEEEEECO

$\longrightarrow$ $->$

CCCCCEEEEEEEECCCCCCCHHHHHHH

$$
\begin{array}{llll}
\text { i30 } & \text { i40 } & \text { í50 }
\end{array}
$$

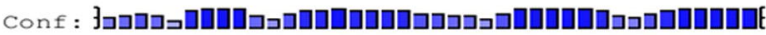

Pred:

AA: LLVLAGGPGPGHLAALARVQAERSSGGPGPGRVGLAVVLW

$$
\text { ín } \quad \text { iso } 190 \quad \text { 2ं00 }
$$

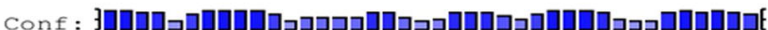

Pred:

Pred: HHHHCCCCCCCCEEEEEEECCEEEEECCCCCCEEEEEEEE AA: SLLWLGGPGPGAALLVVAVGLRVVCAGPGPGALDILFIIS

$$
\begin{array}{llll}
\dot{2} 10 & \dot{2} 20 & \dot{2} 30 & \dot{2} 40
\end{array}
$$

Conf : \} ל Pred: $>-\longrightarrow$

Pred: ECEECCCCCCCCEEEEEECCCCCCCCHнHнHCCCCCCEE AA: TTIHTAKKPTGATVVQFEKKWDPTPMEHEQKKMAPGRVGL

$250 \quad 260 \quad 270 \quad 280$

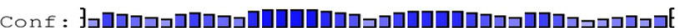

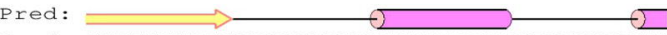

Pred: EEEEEEEEEECCCCCCCCCCHHHHHHHHHCCCCCCCCCHH

AA: AVKKVKRVYHIQPSKKPKQVPLAMAYKKAFAPQSLLVGKK

$$
\text { 290 3ं00 3ं10 3ं20 }
$$

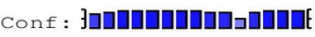

Pred:

Pred: HHHHHHHHHHHCCCC
AA: AKFVAALKAAAGGGS

330

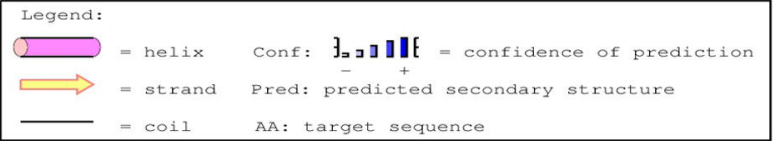




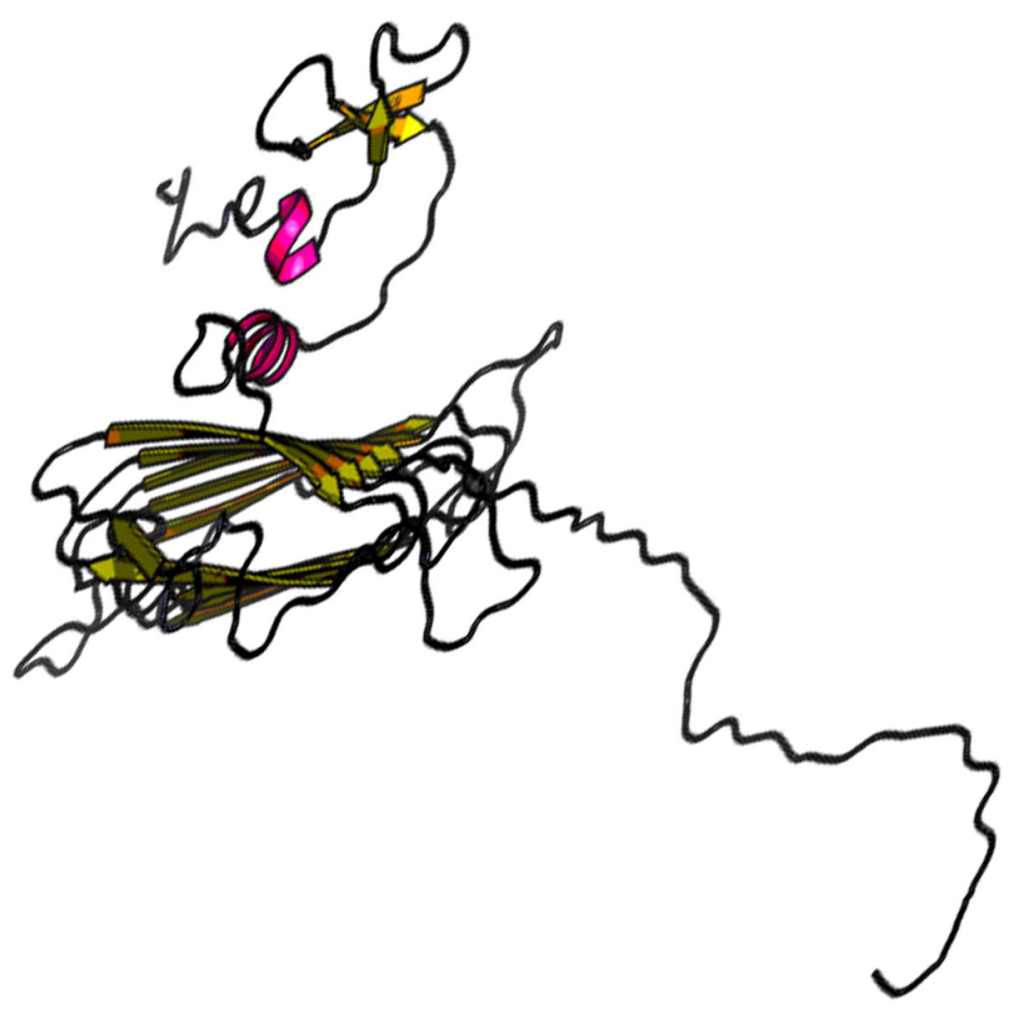

A

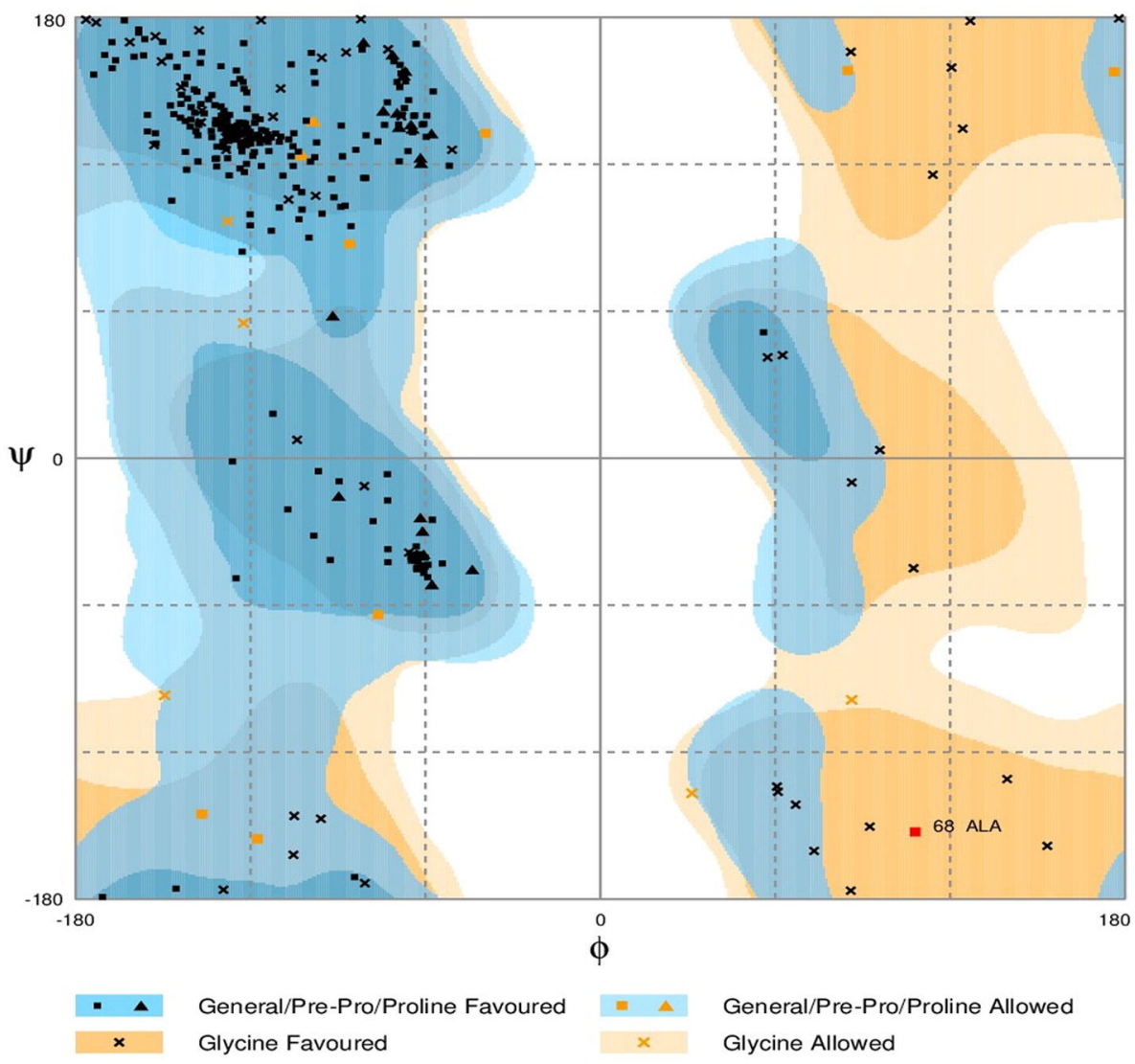

B 


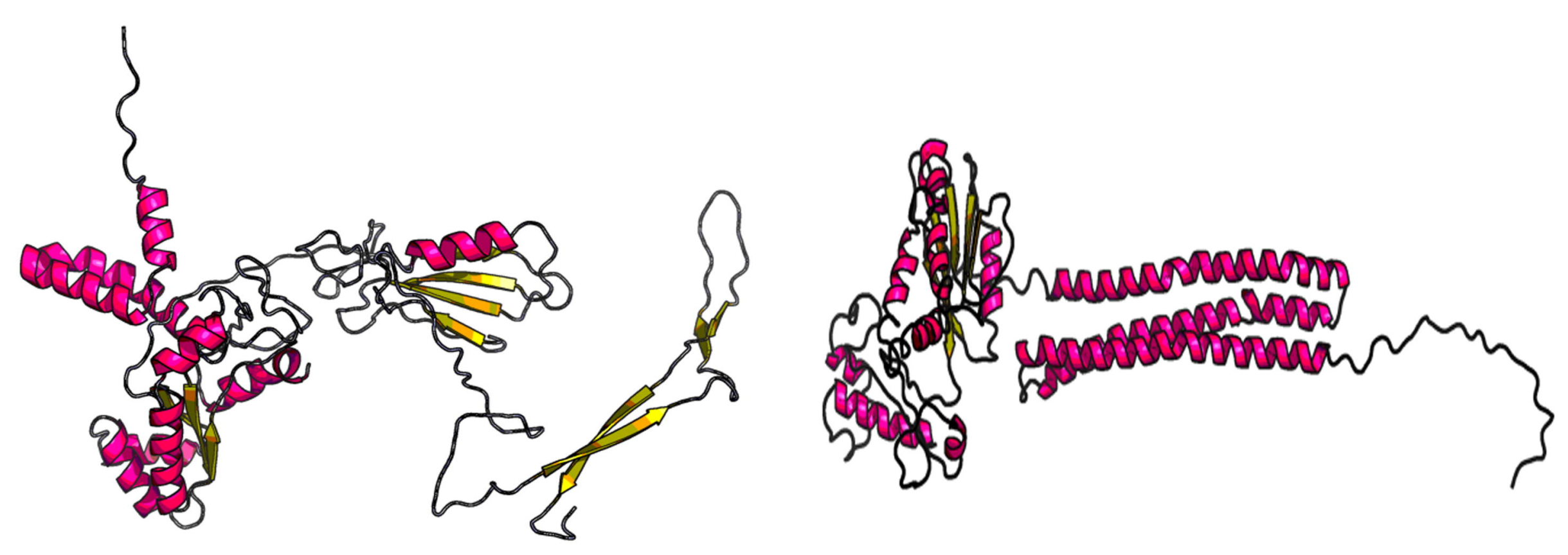




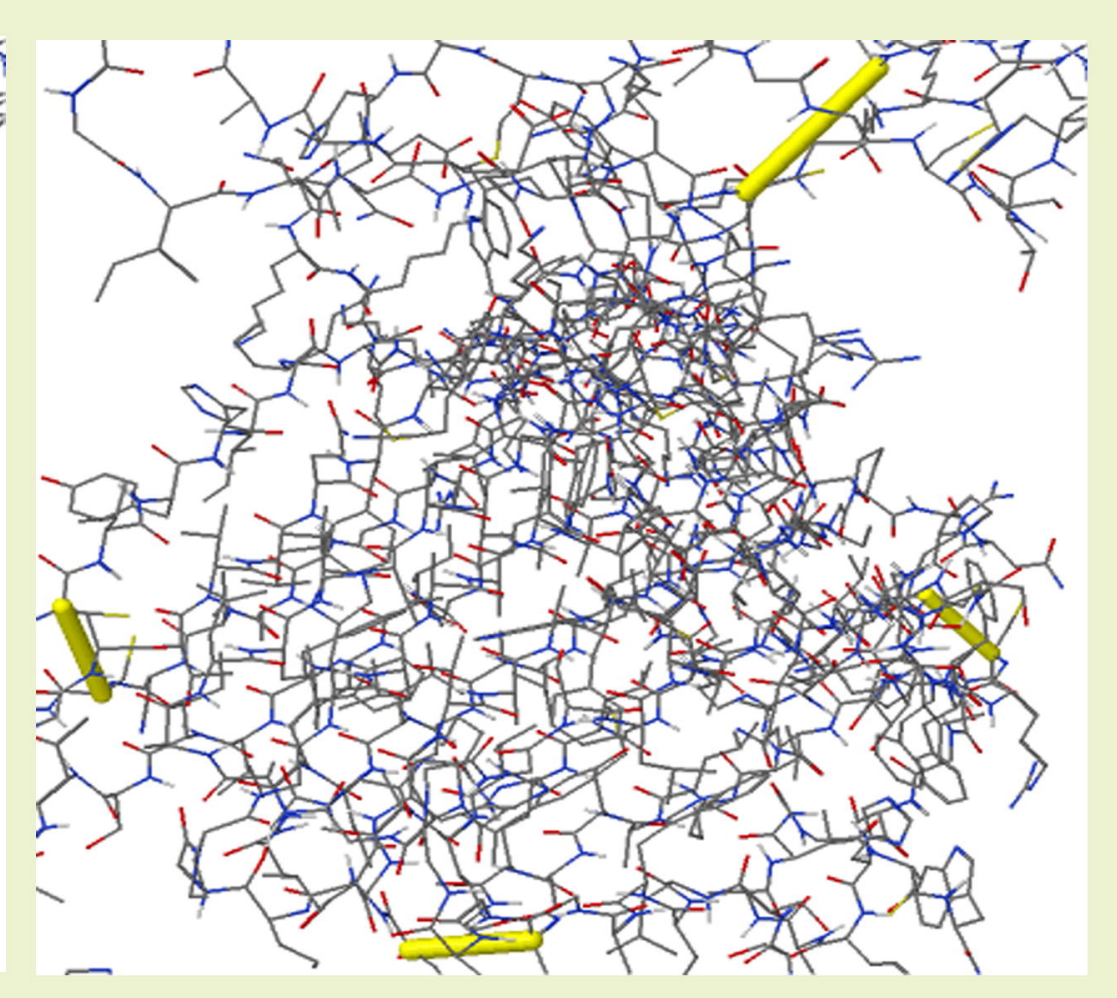



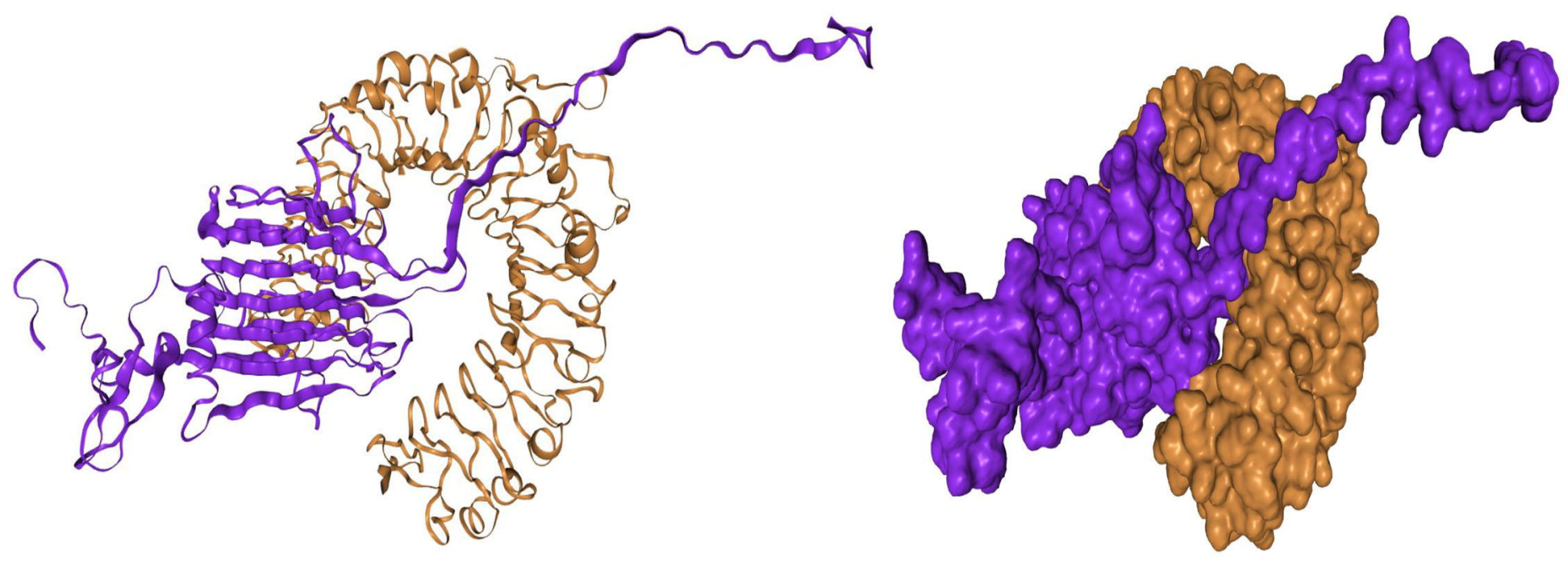

A

B 


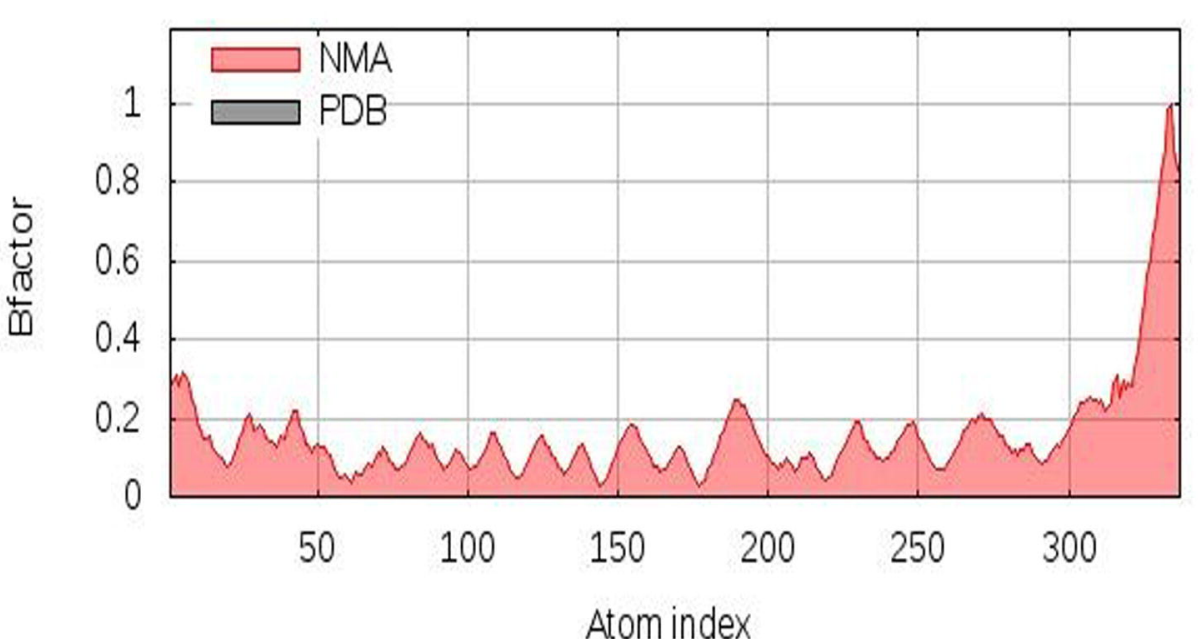

A

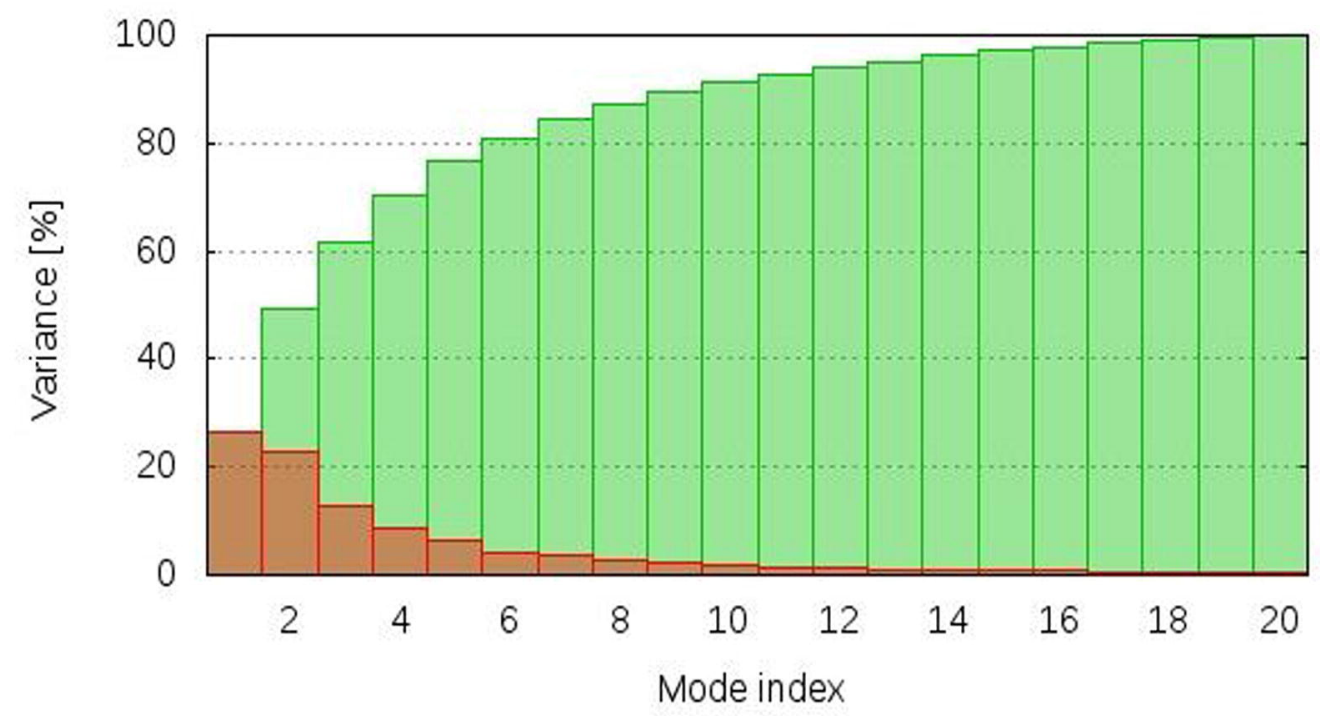

C

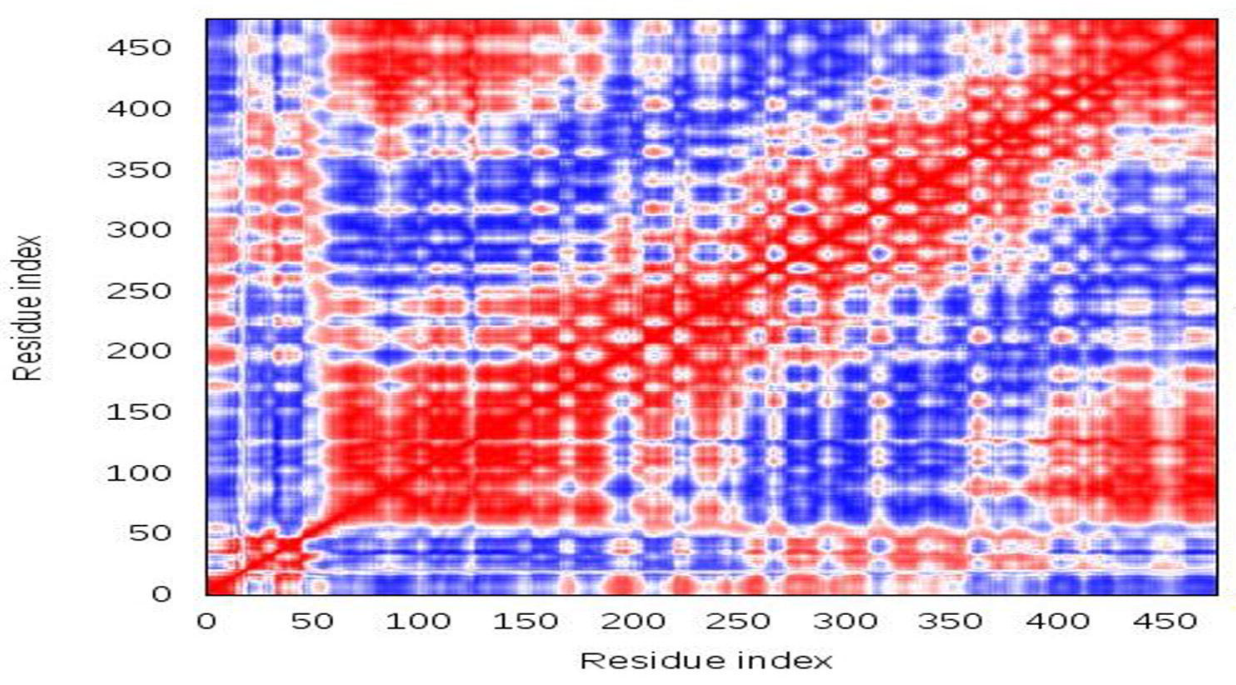

E

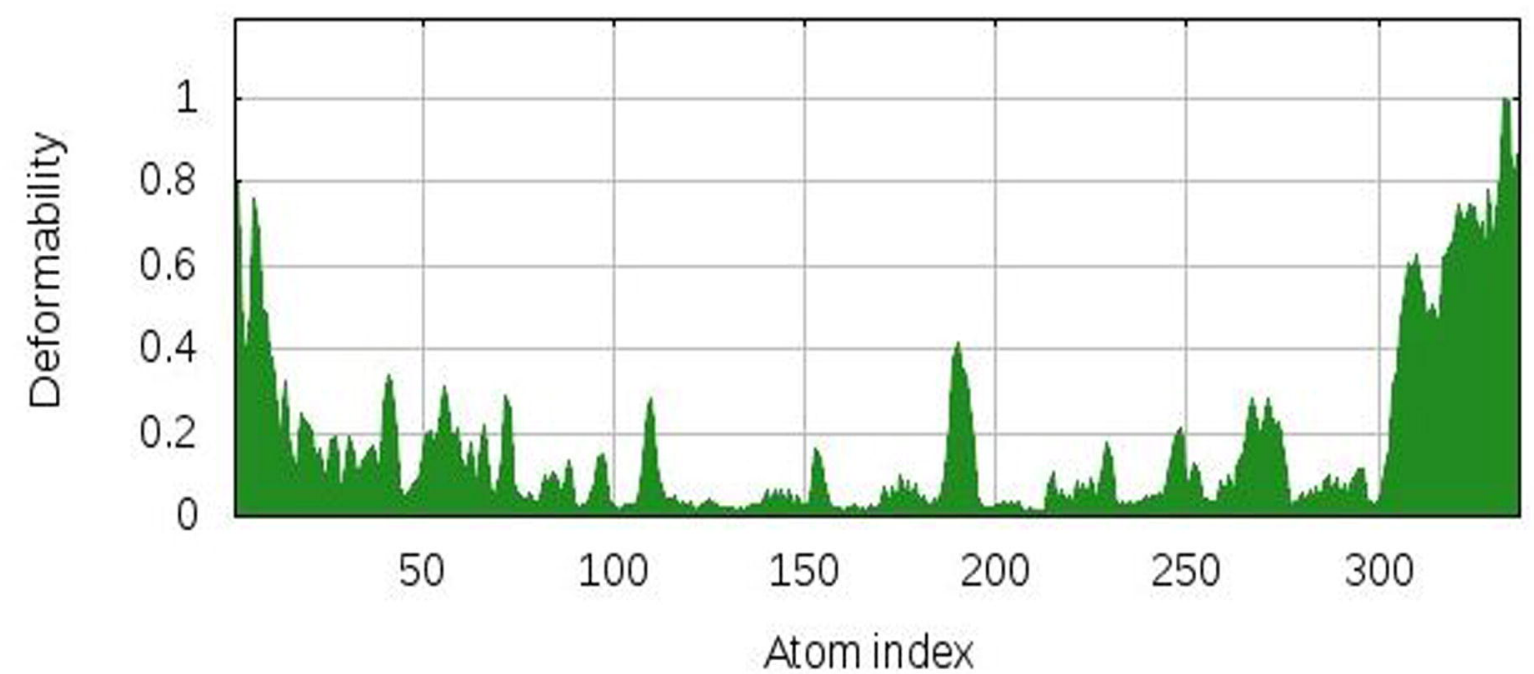

B

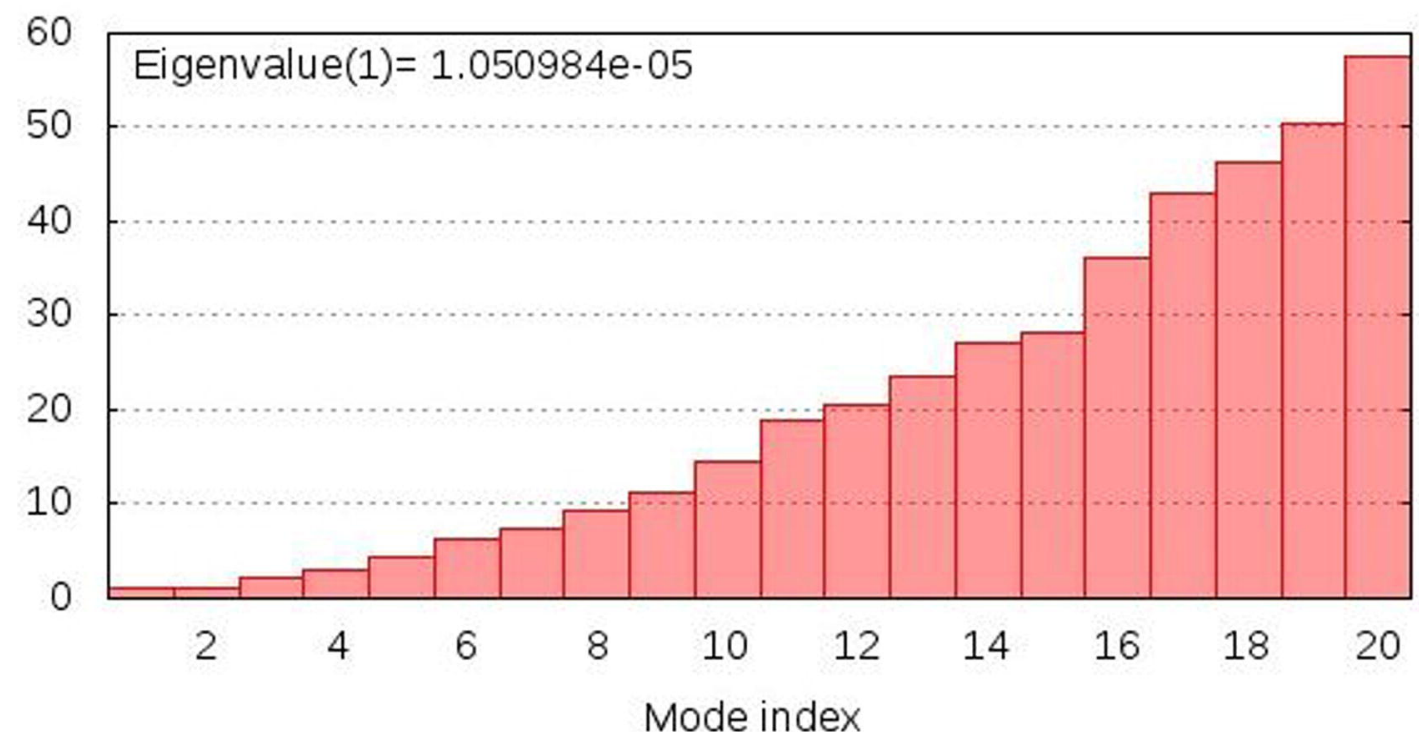

D

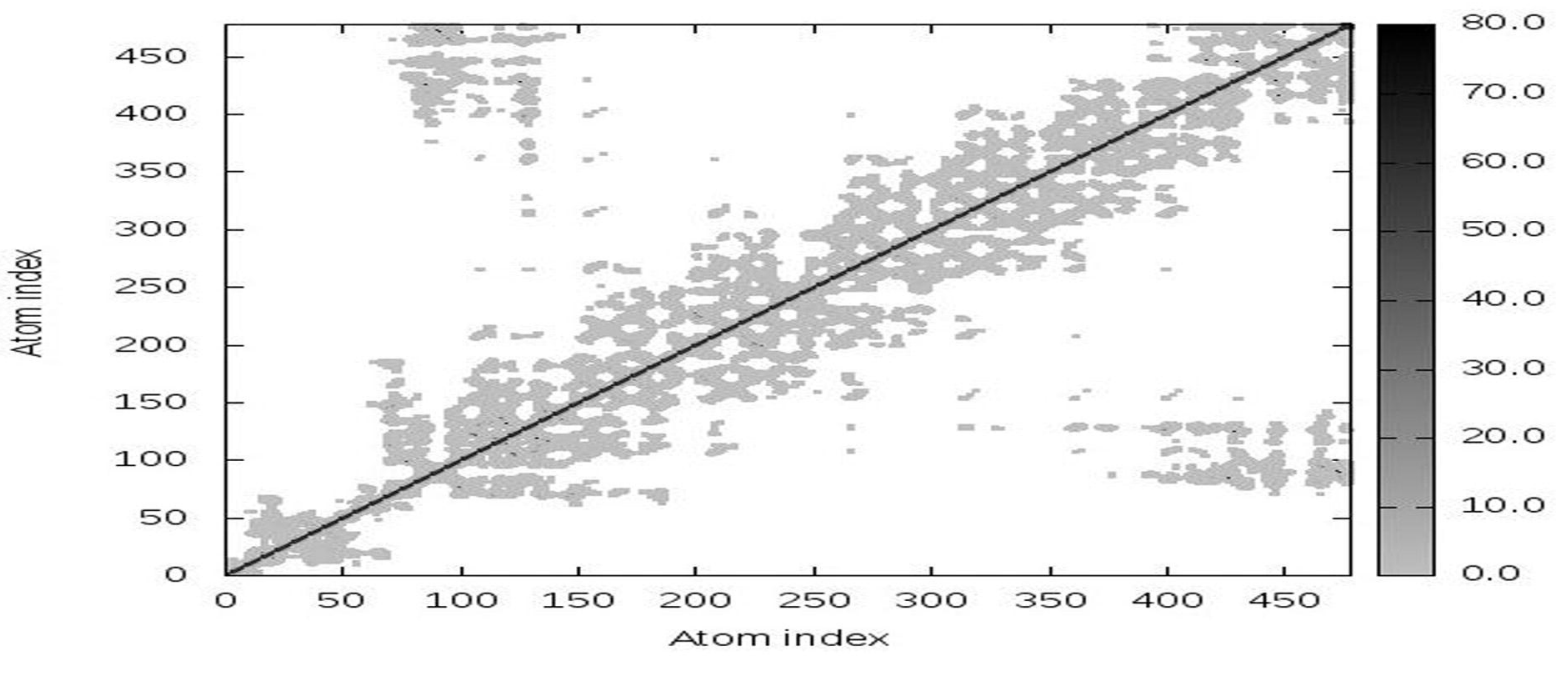




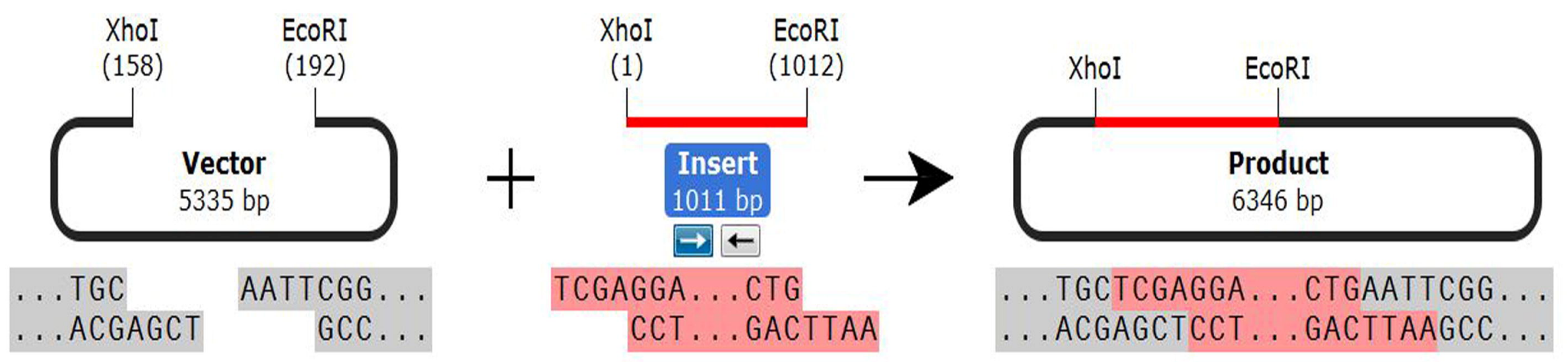

$A$

bioRxiv preprint doi: https://doi.org/10.1101/679639; this version posted June 24, 2019. The copyright tolder for this preprint (which was not certified by peer review) is the author/funder. All rights reserved. No reuse allowed without permission.

(80) BIpI

(6104) DraIII

(5976) PsiI

(5094) BspDI - ClaI (5060) NruI

(5403) AsisI - PvuI

(4749)

(5277) SmaI (5275) XmaI

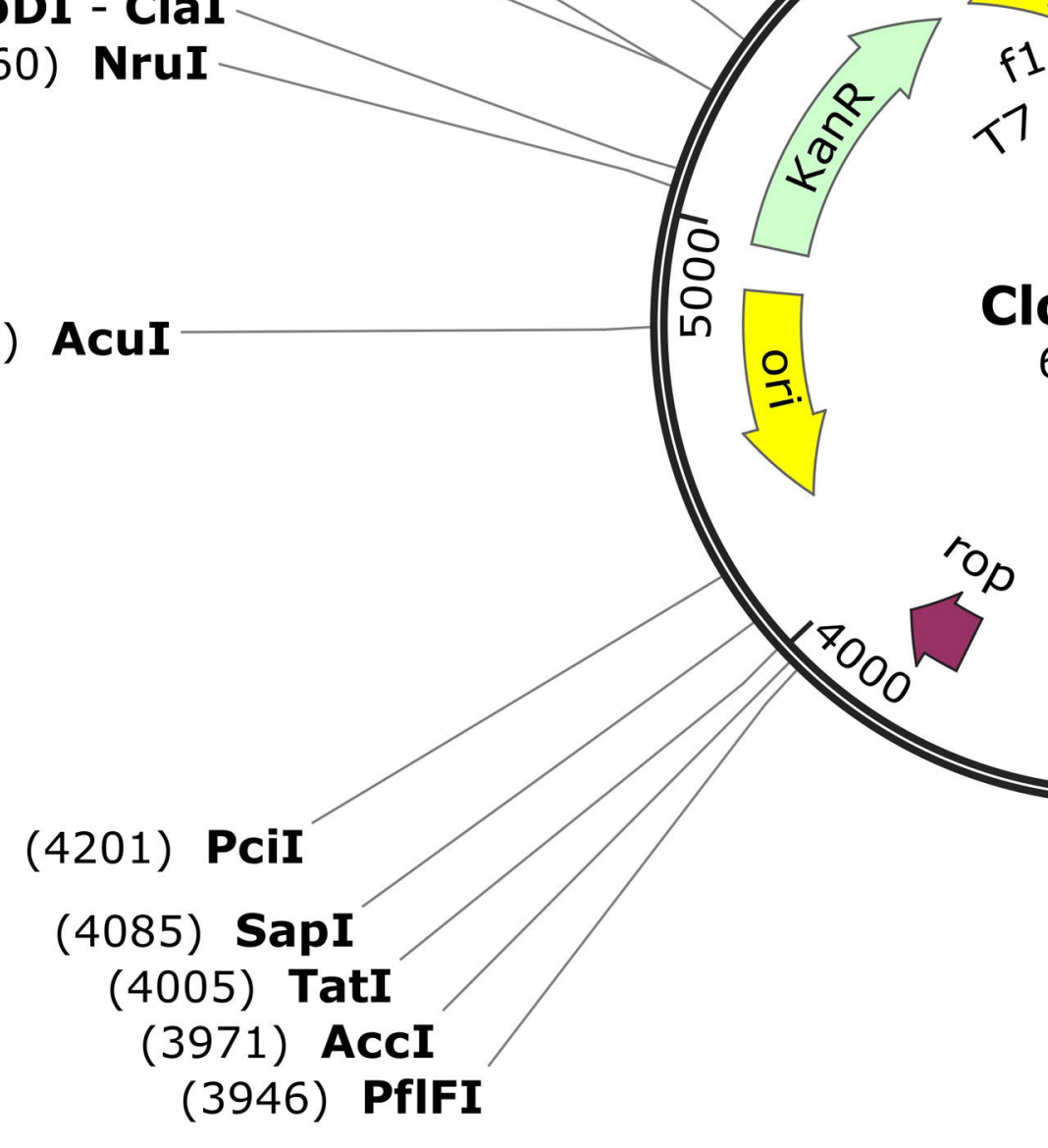

(3182) FspI

Cloned V1

$6346 \mathrm{bp}$

Created with Snap Gene

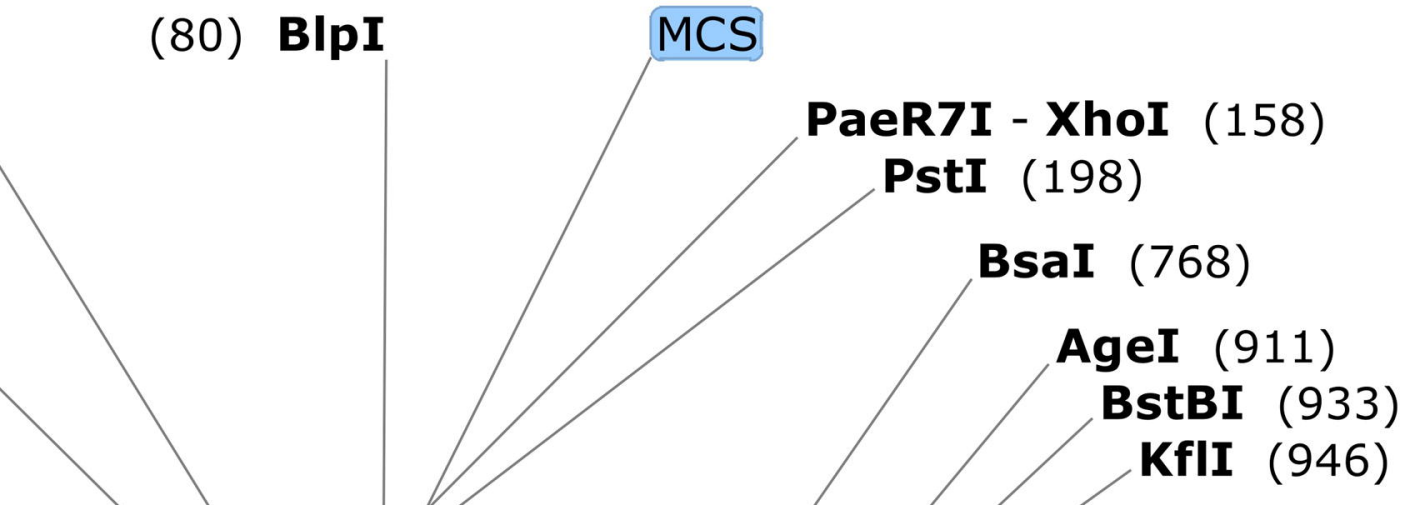

